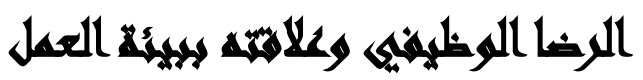

\section{$[r \cdot]$}

\author{
محمد عبد العزيز (')- نادر ألبير(')- سها إبراهيم \\ ( ) كلية التجارة ، جامعة عين شمس علد العزبز
}

\section{المستخليك}

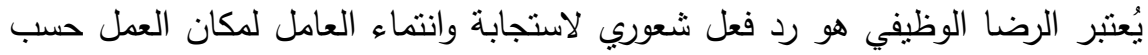

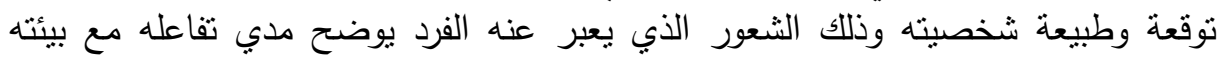
العملية من خلال المظاهر المختلفة المرتبطة بالعوامل المؤثرة علي بيئة العمل.

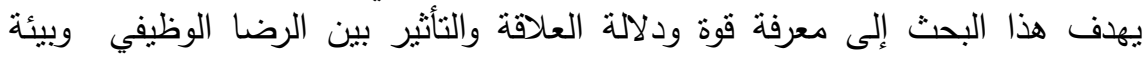

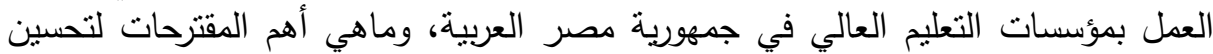
بيئة العمل لتحقيق الرضا الوظيفي للعاملين.

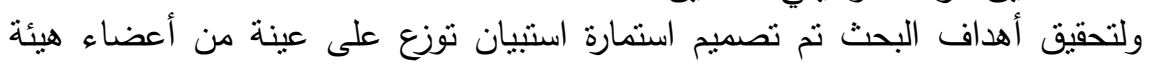

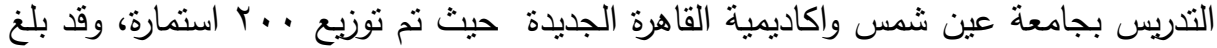

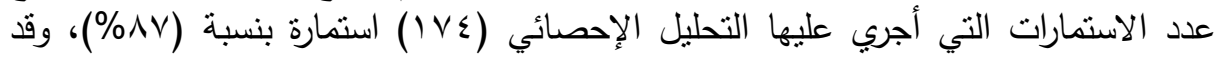

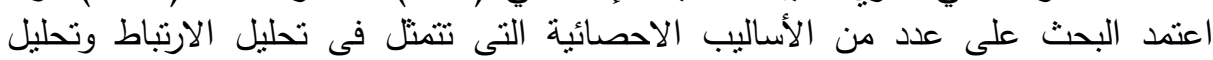

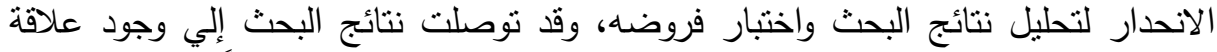

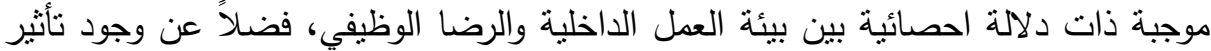

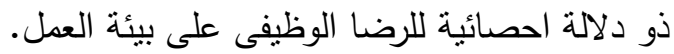

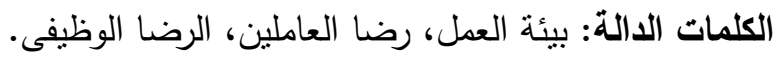

\section{المهanatl}

تسعى معظم المنشآت لتوفر بيئة عمل صحية حيث ترتبط فاعلية أية منظمة بكفاءة العنصر البشري وقدرته على العمل ورغبته فيه باعتباره العنصر المؤثر والفعال في استخدام الموارد المادية المتاحة، وتعتمد الإدارة في تعظيم النتائج على ترشيد استخدام الموارد المادية والبشرية المتاحة حتي لا تؤثر علي انتاجية العمل. وللتنليل على ذلك اثارت دراسة (الثنمري،

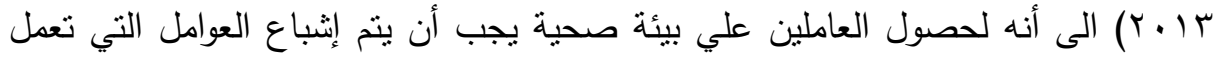


علي الرضا كالأجر والمكافأت، العلاقة مع الزملاء والرؤساء، الاحتباجات الخاصة للنمو والمشاركة في اتخاذ القرارات وبيئة العمل.

كما يفترض (هيرزبرج) في نظرية ذات العاملين أن هناك مجموعة من العوامل المؤثرة

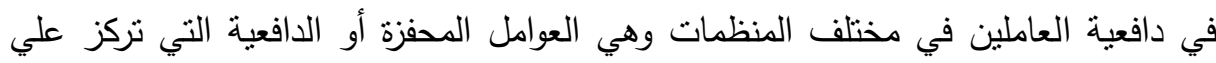
النمو النفسي وتتعلق بمحتوي العمل مثل (الإنجاز، العمل نفسه، التطور، النمو، المسؤلية،

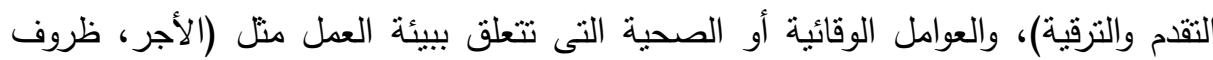
العمل، الإثراف، العلاقة مع الرؤساء والزملاء، الحياه الثخصية والأمن)، وتعتبر هذه العوامل

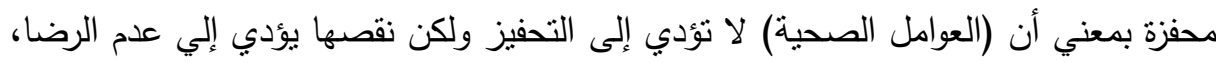

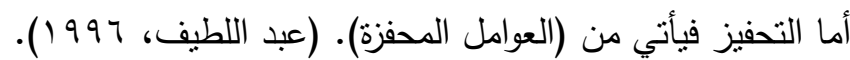
وتؤثر الدوافع على العديد من الظواهر الإنسانية في المنظمة حيث يؤدى عدم اهتمام المنظمة بتتمية الدوافع الإيجابية نحو العمل إلى بروز بعض الظواهر السلبية لدى العاملين،

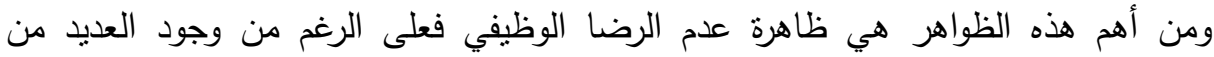

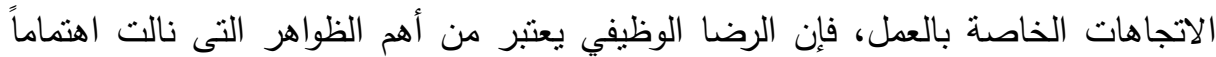

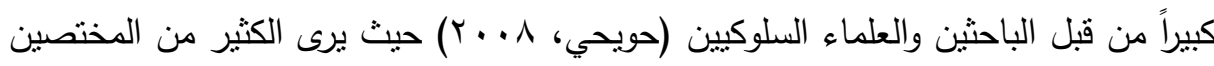
في مجال الأداء وتحسينه أن لبيئة العمل أثز جوهري علي أداء العاملين وأن المقصود بمفهوم بيئة العمل هو كافة العمليات كالأنظمة، القوانين، الثقافة، السياسات، والقواعد إلي جانب بيئة العمل الخارجية، فتلك العوامل في غيابها تؤدي إلي عدم الرضا والتي تتفاوت درجة رضاها من فرد لآخر مع التأكد على أن العاملين قادرون علي إدارة حياتهم اليومية حتي لا نؤثر علي لئي

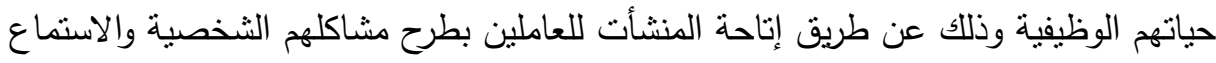

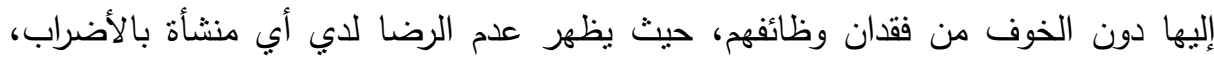
الثكاوب، التمارض، والغياب المتكرر مما يؤدي إلي تدهور أداء المنظمة وانتاجيتها. (حسن، 


\section{السراسايت السابرية}

تعددت الدراسات التي تتاولت الرضا الوظيفي، وكذلك الدراسات التي تتاولت بيئة العمل

الداخلية، إلا أن هنالك ندرة فى الدراسات التى نتاولت علاقة الرضا الوظيفي بييئة العمل

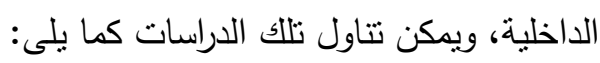

الاراسات السابقة حول الرضا الوظيفى: تتاولت العديد من الدراسات الرضا الوظيفى من حيث محدداته الأساسية، والعلاقة بين الرضا الوظيفة وكل من نوع المكتب، سهولة تعامل الموظفين، تغيير مكان العمل، ممارسات التسويق الداخلى ذات الجودة العالية، الالتزام التتظيمى والخصائص الديموغرافية، والالتزام المهنى، ويمكن نتاول نلاك الدراسات كما يلى Yuen et. al., (2018): Determinants of job satisfaction and performance of seafarers

هدفت هذه الدراسة تحليل المحدات الأساسية للرضا الوظيفي وأداء البحارة، وقد أجريت

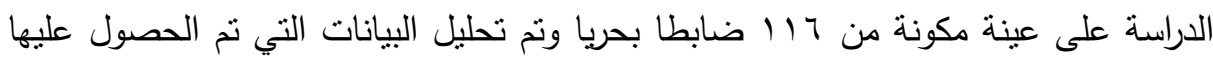
باستخدام المعادلات الهيكلية. وقد خلصت نتائج الدراسة إلى وجود ارتباط بين الرضا الوظيفي والأداء الوظيفي للبحارة،

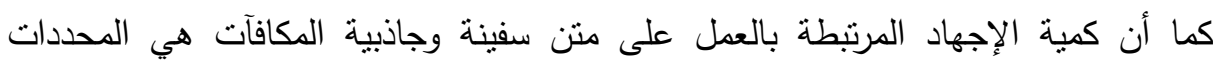
الرئيسية للرضا الوظيفي، فضلاً عن وجود تأثثر معنوى لظروف البحارة وتصميم الوظيفة على لئل الرضا الوظيفي.

Otterbring $e t . a l .$, (2018): The relationship between office type and job satisfaction: Testing a multiple mediation model through ease of interaction and well-being

هدفت هذه الدراسة فحص العلاقة بين نوع المكتب وسهولة تعامل الموظفين مع زملاء العمل، والرفاه الثخصي، والرضا الوظيفي، حيث تم تصميم استبيان موجز يتضمن مقاييس نوع المكتب، وسهولة التفاعل مع زملاء العمل، والرفاه الثخصي، والرضا الوظيفي إلكترونيا،

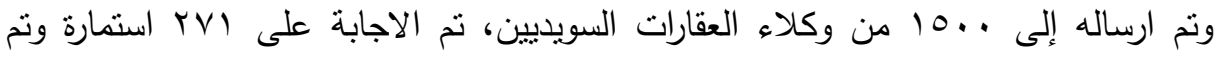
تحليل البيانات باستخدام نموذج الانحدار المتعدد الذي اختبر العلاقة بين نوع المكتب والرضا فلهاء الوظيفي سوف توسط بيسر التفاعل، وبالتالي الرفاه الثخصي، وقد توصلت النتائج الى وجود

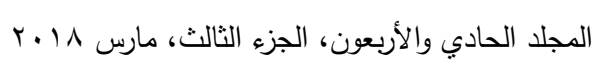


علاقة سلبية بين عدد زملاء العمل الذين يشتركون في الرضا الوظيفي للمكاتب والموظفين. وقد توسطت هذه الرابطة بشكل متسلسل من خلال سهولة التفاعل مع زملاء العمل والرفاهية الثخصية، مع الموظفين العاملين في المكاتب الصغيرة والمتوسطة ذات المخطط المفتوح والافصاح عن مستويات أدنى من كلا الجانبين من الموظفين الذين يعملون في المكاتب

$$
\text { الخلوية أو المشتركة. }
$$

وتم استتتاج انه يمكن أن تكون للمكاتب ذات الخطط المفتوحة فوائد مالية قصيرة الأجل، ولكن هذه المنافع قد تكون أقل من التكاليف المرتبطة بانخفاض الرضا الوظيفي والرفاه. لذلك، يجب على صناع القرار النظر في تأثثر نوع المكتب على الموظفين بدلا من التركيز فقط على تخطيط المكاتب فعالة من حيث التكلفة والمرونة والإنتاجية.

Chadi, A. \& Hetschko, C. (2018): The magic of the new: How job changes affect job satisfaction

هدفت هذه الدراسة التحقق من العلاقة بين للرضا الوظيفي وتغيير مكان العمل حيث توضح الدراسة ان التوظيف السابق يرتبط ارتباطا وثيقا بالرضا عن الوظيفة الجديدة. فعندما

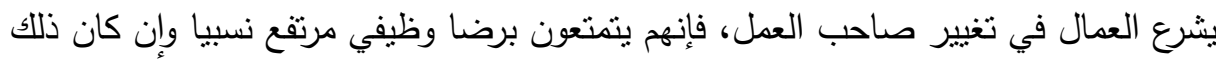
على المدى القصير فقط، وقد توصلت الدراسة الى مجموعة من النتائج تتعلق برفاه العمال وكذلك سياسات سوق العمل والموارد البشرية وأهم هذه النتائج:ا. إن بدء العمل لدى صاحب عمل مختلف يرتبط، في المتوسط، برضا وظيفي مرتفع جدا. r. تأثثر الوظائف الجديدة كثفت عنها غالبية التغييرات الطوعية في الوظائف.

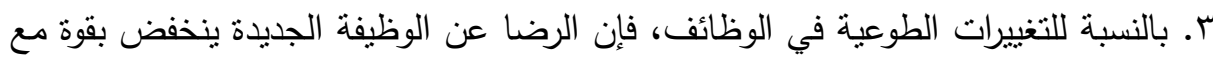

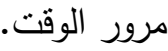

Marques et. al., (2018): Internal marketing and job satisfaction in hotels in Via Costeira, Natal, Brazil

هدفت هذه الدراسة تقييم أثز ممارسات التسويق الداخلي في الفنادق ذات الجودة العالية في مدينة نانال في شمال شرق البرازيل على رضا والتزام العملاء الداخليين، وقد تم جمع مقاييس التوجه الداخلي للسوق، والالتزام التتظيمي، والرضا الوظيفي لعينة من ^با مديرا

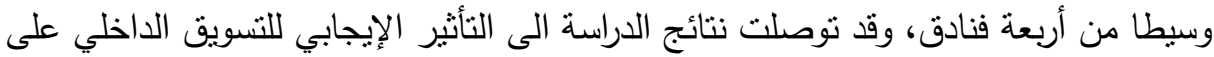
484

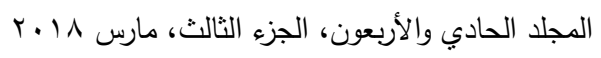


الالتزام التتظيمي والرضا الوظيفي لكنها تقشل في تأكيد العلاقة المنوقعة بين الالتزام والرضا الوظيفي.

Cherian, et. al., (2018): Relationship Between Organizational Commitment and Job Satisfaction of Nurses in Dubai Hospital

هدفت الدراسة فحص العلاقة بين الرضا الوظيفي للممرضات والخصائص الديموغرافية

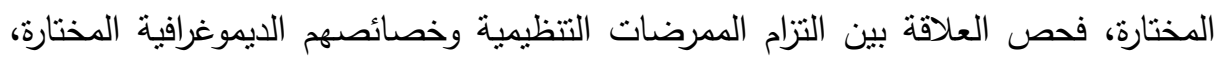
فضلاً عن تقييم العلاقة بين رضا والتزام الممرضات التظيمية تجاه تتظيمهم الوظيفي في ولئي مسنتشفى دبي.

وقد قامت الدراسة باجراء تصميما استكثافيا للحصول على نظرة ثاقبة على الالنزام

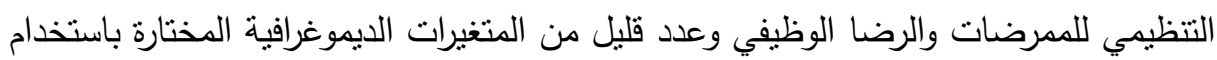
استبيان موحد وزع على . ^r ممرضه ومن ثم دراسة العلاقة بين التزام الممرضات والرضا الوظيفي.

وقد توصلت نتائج الدراسة إلى أن غالبية الممرضات (7 9\%) على استعداد لتوصية

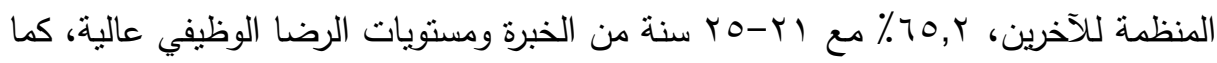

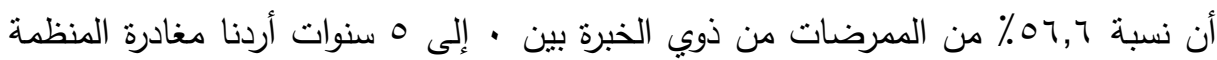

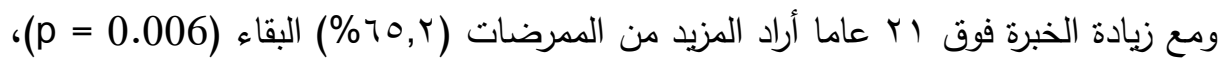

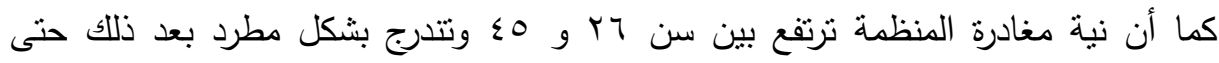

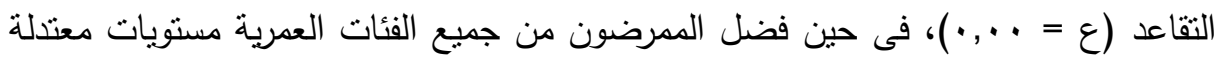

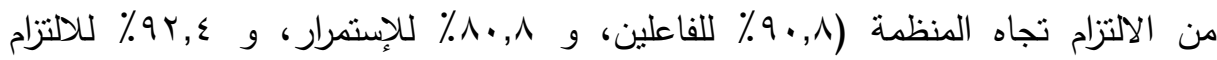

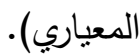

وقد لوحظت علاقة مهمة بين الرضا الوظيفي ومستويات الالتزام التنظيمي بين الممرضات (ع = 7 . ., ·) حيث كان الرضا الوظيفي الإجمالي للممرضين مرتبطا بشكل

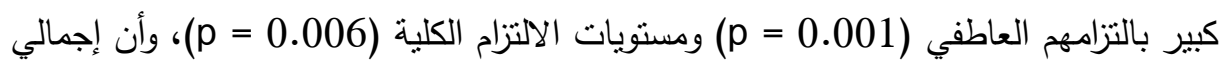
منسوبي التمريض كانت مستويات الالتزام التتظيمي مرنبطة ارتباطا كبيرا برضاهم الوظيفي الخارجي (p=006) ومجموع مستويات الرضا الوظيفي (p =0.006).

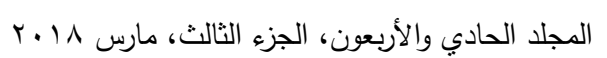


Tasneem, et. al,. (2018): Job Satisfaction of Health Service Providers Working in a Public Tertiary Care Hospital of Pakistan أثنارت الدراسة الى أنه لا يمكن إقامة نظام صحي فعال دون وجود قوة عاملة راضية حيث أن العديد من المهنيين غير راضين مما قد يؤدي الى إنهاء مهنتهم أو ترك وظائف بحثنا عن فرص أفضل، ولهذا السبب اكتسب موضوع الرضا الوظيفي اهتماما في قطاع الرعاية الصحية العامة والموارد البشرية في باكستان في الماضي القريب، وقد أجريت هذه الدراسة على العاملين في الرعاية الصحية في المستشفى العامة لتحديد العوامل المختلفة. وقد نم جمع البيانات باستخدام طريقة أخذ العينات غير الاحتمالية لأخذ العينات الملائمة في الأماكن العامة في مستثفى روالبندي الذي يوجد فيه أكثر من . . . سرير، باستخدام استبيان ووزع ما مجموعه 110 استنيانا وجمعت على مدى شهرين، منها 19 لم تكن هناك

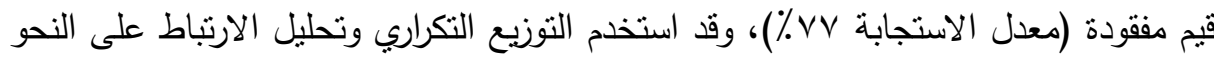
المقترح حيث أظهرت نتائج الدراسة أن غالبية العاملين راضون وفيثن عن المشرفين وطبيعة العمل والزملاء، ولكنهم أبدوا عدم رضاهم عن بقية العوامل منل الرواتب والفوائد والاتصالات والظروف في العمل.

وقد اوصت الدراسة بضرورة عدم تجاهل أهمية القوى العاملة الصحية بالرضا الوظيفي حيث يؤدى ذلك إلى تحسين جودة الخدمات الصحية التي يتم توفيرها للمستهلكين من النظام

Sari, R. L. \& Seniati, A. N. L. (2018): The role of professional commitment as a mediator in the relationship between job satisfaction and organizational commitment among lecturers in higher-education institutions. Diversity in Unity

أجريت هذه الدراسة من أجل إيجاد دور الالتزام المهني كوسيط في العلاقة بين الرضا

الوظيفي والالتزام التتظيمي بين المحاضرين في مؤسسات التعليم العالي. وقد أجريت الدراسة التطبيقية على عينة مكونة من رr محاضرا من / 1 مؤسسة للتعليم العالي في جاكرتا، تانجيرانج، دنباسار، جيمباران، وبادانج، كمستجييين. وكان المحاضرين الأساتذة الدائمين الذين كانوا يعملون في المؤسسات لأكثر من عامين، وشملت أولئك الذين كانوا موظفي الخدمة 
المدنية (PNS) والموظفين غير المدني (PNS). وتتكون مؤسسات التعليم العالي من الجامعات الحكومية (PTN)، الجامعات الخاصة (PTS)، والكيان قانوني الجامعات الحكومية (PTN-BH) ومقياس الالتزام المهني. تم إجراء تحليل وساطة بسيط باستخدام ماكرو بروسيس. وقد توصلت نتائج الدراسة إلى وجود آثار مهمة إيجابية للرضا الوظيفي على الالنزام

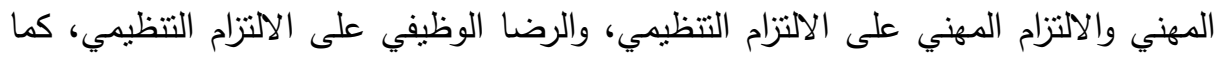
خلصت الدراسة إلى أن الالتزام المهني هو وسيط جزئي في العلاقة بين الرضا الوظيفي والالتزام التنظيمي بين المحاضرين في مؤسسات التعليم العالي مما يشير إلى أن مؤستسات

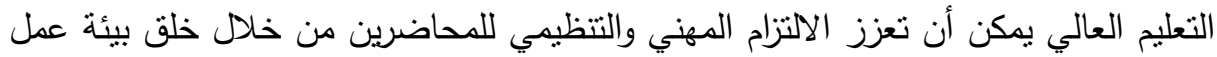
أكثر مرضية.

استعرضت الباحثة من خلال الدراسات السابقة علاقة الرضا والوظيفي بمجموعة من المتغيرات المختلفة والتى اجريت في بيئة مختلفة مثل الامارات، باكستان، البرازيل وغيرهما،

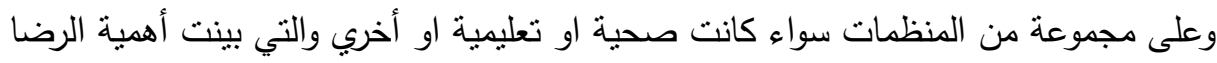
الوظيفي وعلاقته الايجابية بتلك المتغيرات.

الدراسات السابقة حول بيئة العمل: تتاولت العديد من الدراسات أهمية بيئة العمل وعلاقتها ببعض المتغيرات المنمنلة فى الأداء الوظيفى، مدركات السلوك السياسى وبعض لهارل الكترتبات الاتجاهية المحتملة كإدراك الضغوط الوظيفية، الدعم الاجتماعى داخل المنظمة، الموارد، الحرية، اللوائح، قيمة الاحترام المنبادل، الوصول إلى الأهداف، التواصل المفتوح ونظام الدعم القوى، التماسك، القيادة الفعالة، الثفافية والاعتراف، دوران ذوى الخبرة، خصائص العمل والمشاركة فى العمل، ويمكن تتاول تلاك الدراسات كما يلي: دراسة رحمون(؟ ا ـ r): بيئة العمل الداخلية وأثرها على الاداء الوظيفي: تتاولت هذه الدراسة

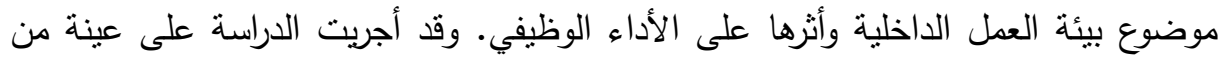

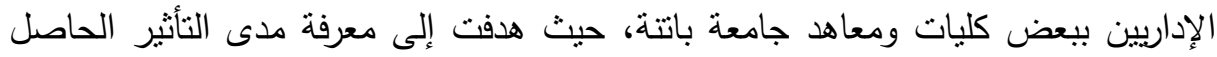
بين بيئة العمل الداخلية والأداء الوظيفي للإداريين ومعرفة الإيجابيات والسلبيات التي تتعكس بلهن

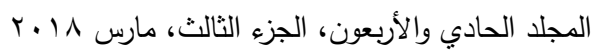


على أدائهم الوظيفي في ظل تلك البيئة، وذلك بالتعرف على مدى استيفاء بيئة العمل الداخلية لعناصرها الإدارية والمادية المكونة لها، ومدى رضا الإداريين عن بيئة عمهم الداخلية ورضاهم عن عناصرها، إضافة إلى التعرف على مستوى الأداء الوظيفي للإداريين من خلادل

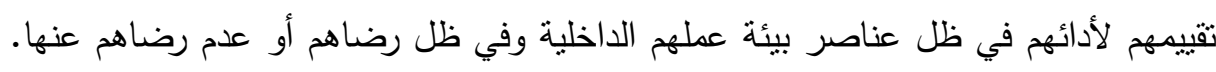
وقد تم استخدام المنهج الوصفي في دارسة مدى التأثير بين بيئة العمل الداخلية كالأداء

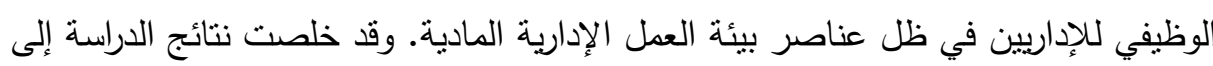

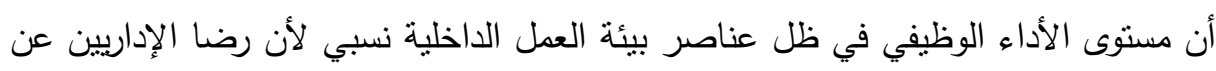

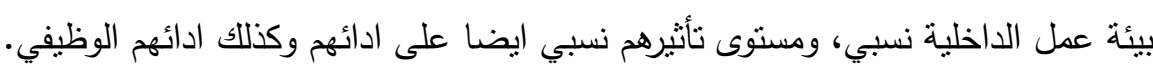

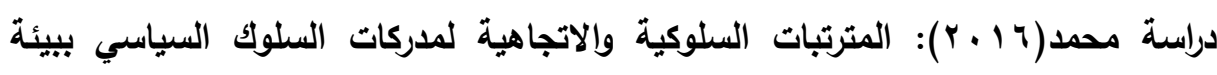
العمل - دراسة تطبيقية

استهدفت الدراسة التعرف على طبيعة العلاقة بين مدركات السلوك السياسي وبعض كاتس

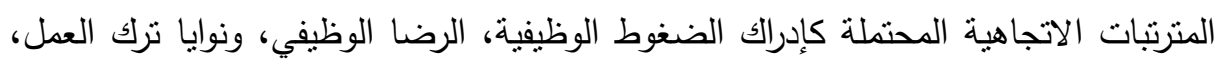

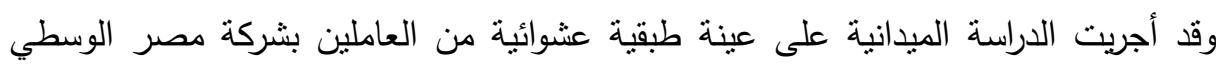

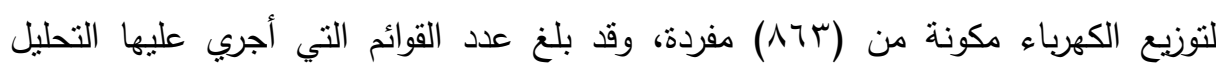

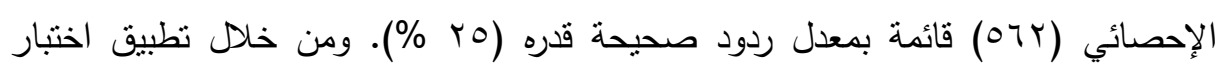

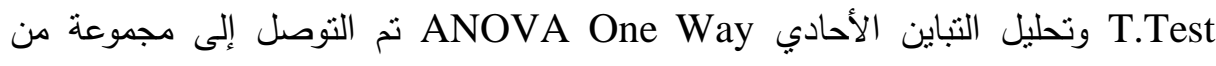
النتائج أهمها وجود فروق جوهرية بين الذكور والإناث في مدركات السلوك السياسي بييئة

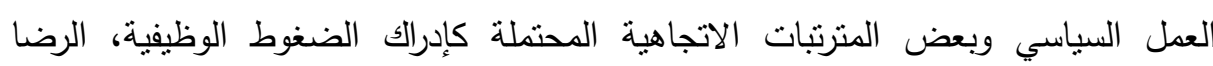

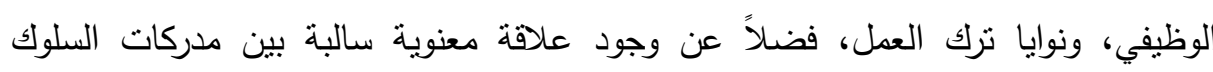
السياسي وكل من الرضا الوظيفي ونية ترك العمل.

Ristic, M. R.; Selakovic, M. \& Qureshi, T. M. (2017): Employee motivation strategies and creation of supportive work environment in societies of post-socialist transformation

استهدفت هذه الدراسة تحديد العوامل المحفزة للموظفين العاملين في القطاع العام في

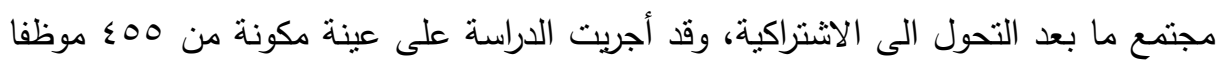


من مختلف الخلفيات التعليمية والمهنية في صربيا وهي الدولة التي تمر بعملية التحول ما بعد

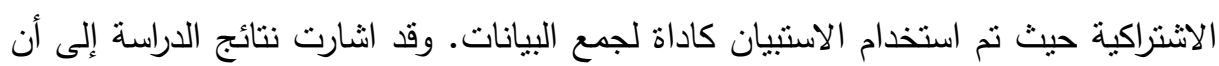

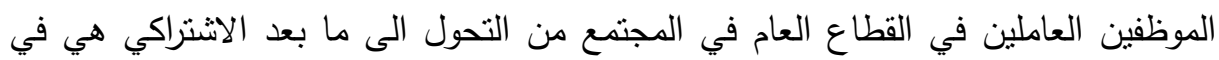

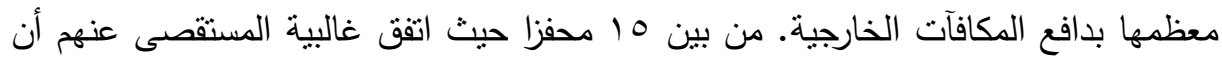
أهم حافز هو رواتب عالية. وفي المركز الثاني وضعوا الترقية، وفي المرتبة الثالثة وضعوا

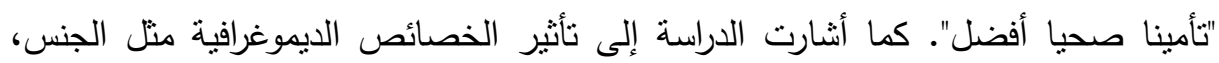
المستوى التعليمي، والمستوى الإداري على دوافع العمل لدى الموظفين الصرب. لماتئ.

Yeh, S. S. \& Huan, T. C. (2017): Assessing the impact of work environment factors on employee creative performance of finedining restaurants

استهدفت هذه الدراسة التحقق من العوامل التي تؤثر على إبداع موظفي المطعم في بيئة

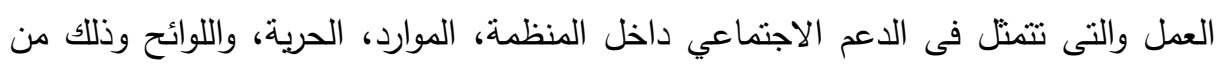

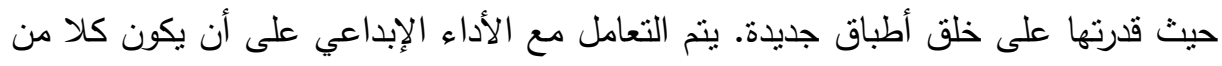

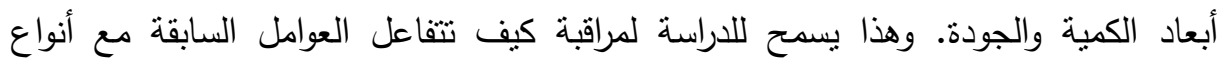
مختلفة من مقاييس الأداء، وقد تم نطوير نموذج واختباره باستخدام استنيان حيث أجريت

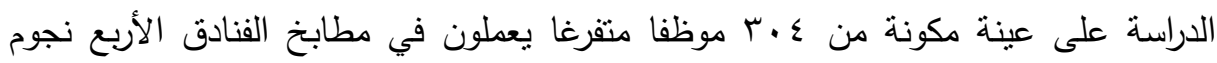
والفنادق الخمس نجوم في تايوان، حيث نم اختبار الفرضيات وتحليل البيانات باستخدام المعادلة الهيكلية (SEM)، وقد توصلت نتائج الدراسة الى أن الموارد يمكن أن تحسن كثيرا

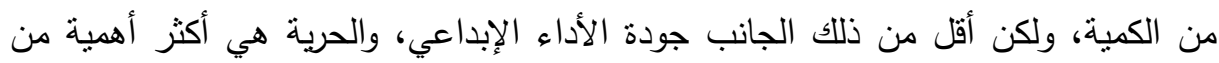

Estimo, E. T. \& Aguilar, G. M. (2017): Understanding Employees' Preferences: Their Work Values, Environment, Interaction and Activities

استهدفت هذه الدراسة الوصفية التعرف على قيم العمل المفضلة والبيئة والتفاعلات

وأنشطة العاملين في المؤسسة البحرية، حيث تم إجراء استنيان لمجموعة من المستجيبين تتكون من 7؛ ا من أعضاء هيئة التدريس الذين يمثلون حجم العينة من إجمالي عدد مفردات

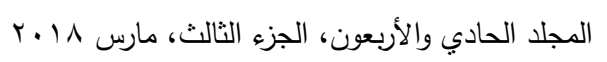


المجتمع البالغ اس T عددهم موظفا، وقد أظهرت نتائج الدراسة أن الموظفين يضعون أعلى قيمة للاحترام المنبادل والوصول إلى الأهداف والتواصل المفتوح ونظام الدعم القوي والتماسك والقيادة الفعالة والثفافية والاعتراف، وبشكل عام فإنها تستجيب بشكل إيجابي إلى بيئة عمل سريعة، موجهة نحو النتائج، ومنظمة. وقد اوصت الدراسة إلى ضرورة مواءمة تفضيلات

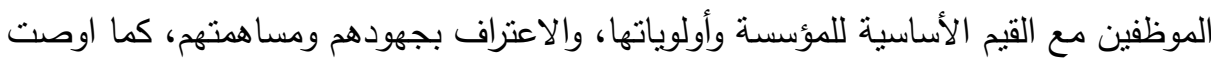
الدراسة بضرورة عقد المزيد من حلقات العمل لتزويد الموظفين بفرصة إعادة النظر في نظام قيمتهم فيما يتعلق بأنفسهم وآخرين في المنظمة، كما يجب إعادة تقييم الأولويات المتعلقة بالعمل أو إعادة تعريفها من خلال حلقات العمل.

Shuck et. al. (2018): Employee Perceptions of the Work Environment، Motivational Outlooks، and Employee Work Intentions: An HR Practitioner's Dream or Nightmare?

استهدفت الدراسة معرفة العلاقة بين تصور الموظفين من بيئة العمل، ونوايا عمل الموظفين، وقد شاركت في هذه الدراسة منظمة تعمل من موقعين هما جنوب كاليفورنيا

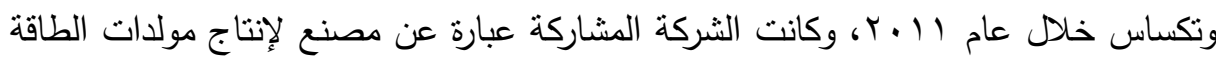
والأدوات الكهربائية في الحديقة والبستتة، ومركبات جميع التضاريس، والدراجات النارية. وكان

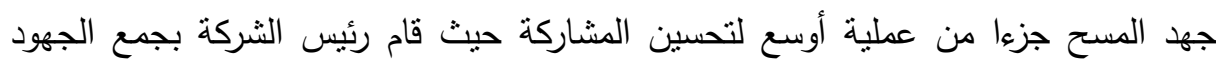
القادمة لجمع البيانات مع فيديو تمهيدي، وقد تم إجراء دراسة استقصائية إلكترونية من خلال

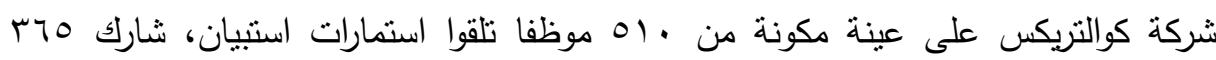

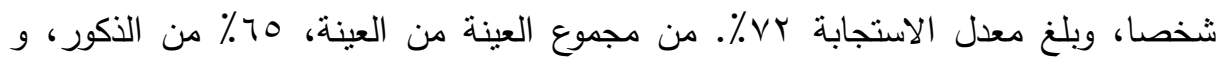

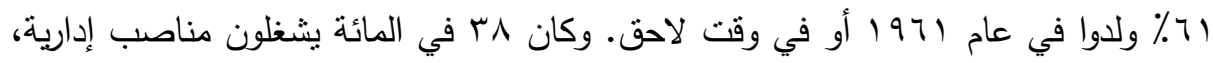
وكان V9 في المائة منهم في المنظمة لمدة ؛ سنوات أو أقل، وقد توصلت نتائج الدراسة الى ولى أن الإدراك البيئي أكثر ارتباطا وقوة أكثر من الدوافع مقارنة مع أنواع أقل ذاتيا من التحفيز ،

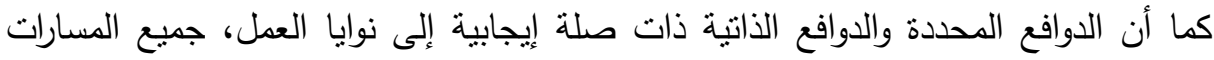
المباثرة من إدراك بيئة العمل إلى نوايا العمل هامة وإيجابية، وكان معظمها معتدلا في الحجم 
مما يشير إلى أن الموظفين ينظرون إلى بيئة عملهم تلعب دورا مباشراً في حباتهم والتحدث

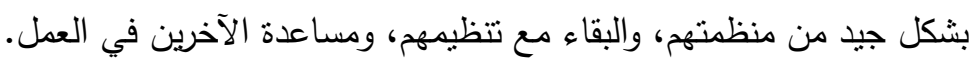

Wan, et. al. (2018): Effects of work environment and job characteristics on the turnover intention of experienced nurses: The mediating role of work engagement

استهدفت هذه الدراسة نقييم نية دوران الممرضات من ذوي الخبرة واستكثاف آثنار بيئة العمل، وخصائص العمل والمشاركة في العمل على نية الدوران.

وقد تم استقصاء عينة مكونة من مجموعه VVA ممرضا من ذوي الخبرة من سبعة فئه

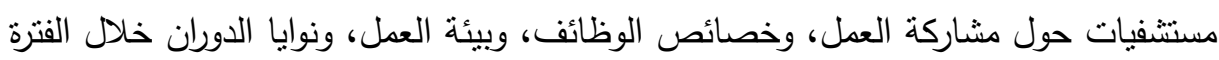

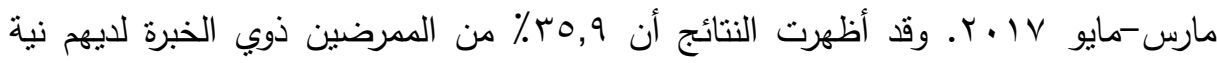

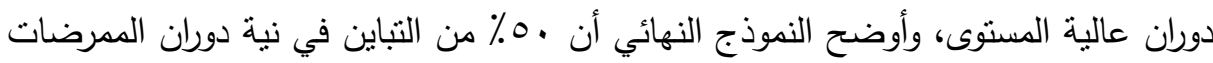

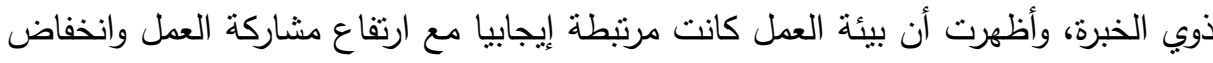
نية الدوران والمشاركة في العمل؛ كما أن خصائص الوظيفة كانت مرتبطة بشكل إيجابي

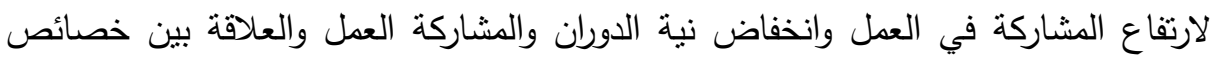

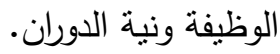
كما أكدت الدراسة إلى وجود ثأثنير جوهري للمحفزات الجوهرية على مشاركة العمل التي يطرحها نموذج متطلبات الوظائف وأن هناك حاجة إلى استراتيجيات لتحسين بيئة العمل، إنهات وتعزيز الخصائص الوظيفية وتعزيز المشاركة ومعالجة نقص التمريض وارتفاع معدل الدوران بين الممرضين من ذوي الخبرة. استعرض الباحث مجموعة من الدراسات السابقة التي تمثل الفجوة البحثية للاراسة الحالية

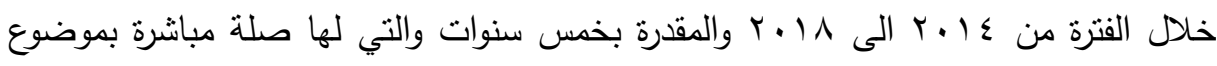
الدراسة الحالية للاستلال منها على حجم المشكلة البحثية ومدى اهميتها والنقص في الدراسات

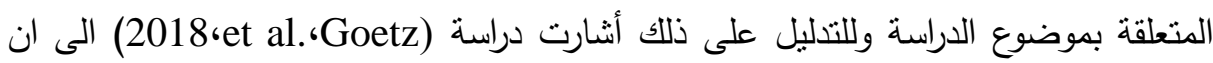
هناك ندرة في البحوث المتعلقة بعلاقة الرضا الوظيفي، وبيئة العمل والخصائص الفردية. 


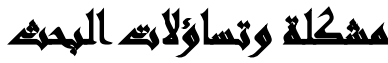

حظي الرضا الوظيفي باهتمام من قبل معظم الباحثن والكتاب نظرا لأهميته وارتباطه

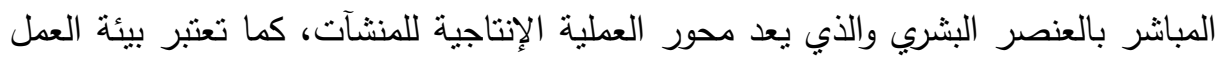

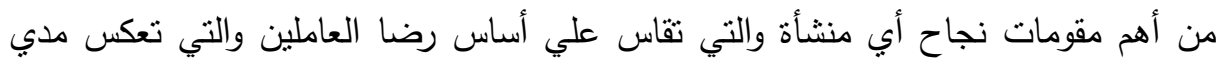

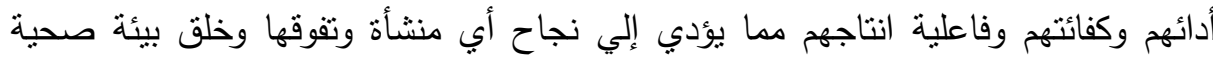

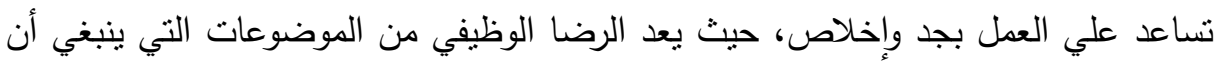
تظل موضعا للبحث والدراسة بين فترة وأخرى وذللك لكونه من الموضوعات الهامة في مجال عملنا وحالة متغيرة بتغير الظروف المحيطة بالعاملين فما يرضى عنه الفرد حاليا قد لا يرضيه

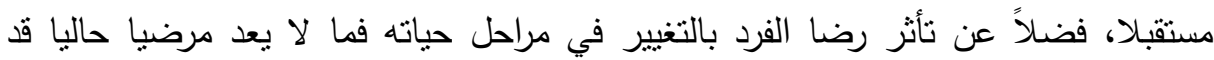
يكون مرضا في المستقبل، وبالنظر لبرامج الإصلاح والتطوير الإداري والتتمية السياسية التي

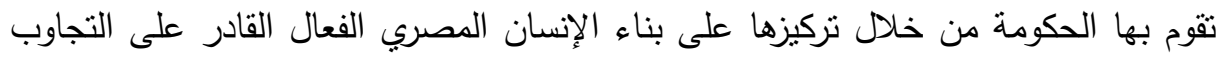

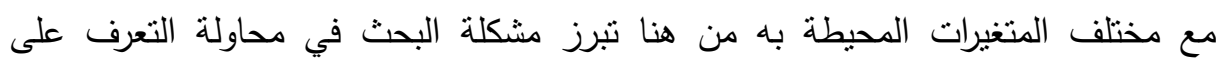

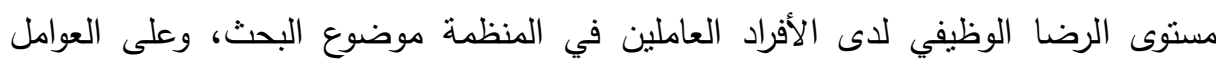

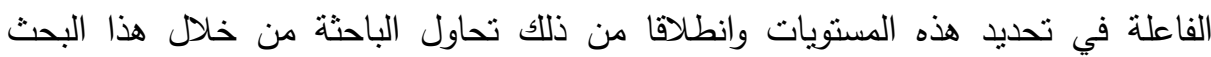

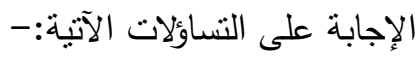


ا. . هل توجد علاقة ذات دلالة احصائية بين الرضا الوظيفي وبيئة العمل في الجامعات العامة والخاصة في جمهورية مصر العربية؟

r. هل يوجد تأثثر ذو دلالة احصائية للرضا الوظيفي على بيئة العمل في الجامعات العامة والخاصة في جمهورية مصر العربية؟ داله داله r. ما هي العوامل المؤثرة علي الرضا الوظيفي داخل مؤسسات التعليم العالي ومؤسسات التعليم الحكومي؟

\section{أهسا اهت المهبث}

يتمتل الهدف الأساسى للاراسة فى تحديد العلاقة بين الرضا الوظيفى وبيئة العمل في الجامعات العامة والخاصة في جمهورية مصر العربية، ويمكن تحقيق هذا الهدف من خلال

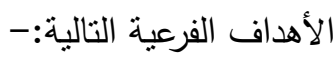
ا. التعرف على درجة العلاقة بين الرضا الوظيفي وبيئة العمل في الجامعات العامة والخاصة

$$
\text { في جمهورية مصر العربية. }
$$

r. تحديد مدى تأثثر الرضا الوظيفي على بيئة العمل في الجامعات العامة والخاصة في

$$
\text { جمهورية مصر العربية. }
$$

r. التعرف على العوامل المؤثرة علي الرضا الوظيفي داخل مؤسسات التعليم العالي

$$
\text { ومؤسسات التعليم الحكومي. }
$$

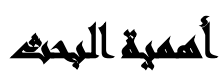

تتبثق أهمية البحث من أهمية الموضوع الذي يتتاوله وهو الرضا الوظيفي داخل

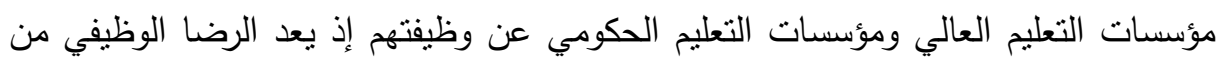

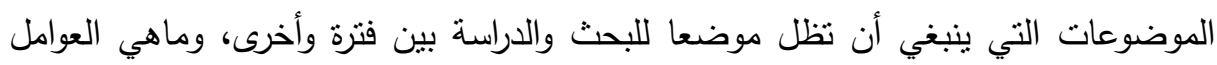
على مستوى هذا الرضا وما يترتب على هذا الموضوع من نأثيرات ايجابية وسلبية على أداء العاملين في المنظمة، علاوة على ذلك ما يأتي:-

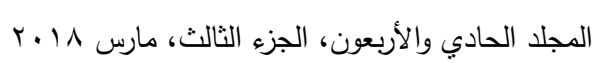


مجلة العلوم البيئية

معهد الدراسات والبحوث البيئية - جامعة عين شمس له

ا. . مساعدة المسئولين والمختصين من خلال ما تتضمنه من حقائق وما تتتهي إليه من نتائج وتوصيات في التعرف على واقع رضا العاملين.

r. المساهمة من خلال ما يقدمه من توصيات ومقترحات لهؤلاء المسئولين على تعزيز هذه الجوانب بما يؤدي إلى زيادة رضاهم وبالتالي زيادة إنتاجيتهم.

\section{هارون الهيثن}

!. توجد علاقة ذات دلالة احصائية بين الرضا الوظيفي وبيئة العمل في الجامعات العامة والخاصة في جمهورية مصر العربية. r. يوجد ثأثير ذو دلالة احصائية للرضا الوظيفي على بيئة العمل في الجامعات العامة والخاصة في جمهورية مصر العربية.

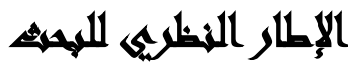

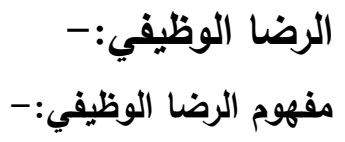

عرف (Stone) الرضا الوظيفي بأنه حاله من التكامل التي يشعر بها الفرد مع وظيفته،

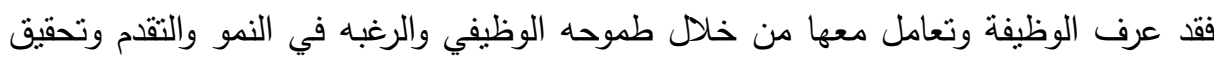

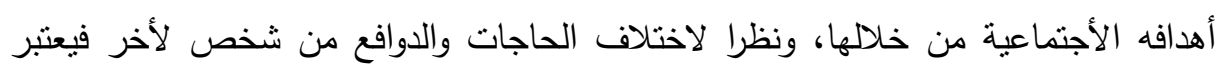

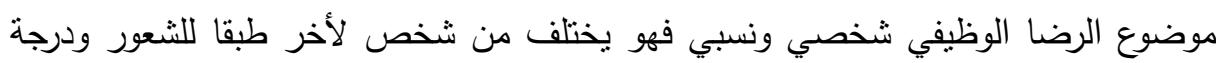

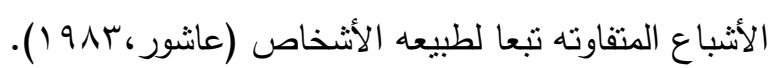

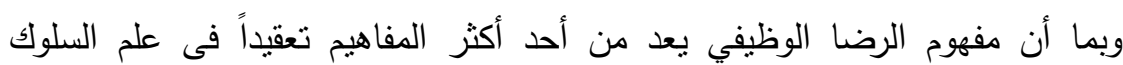

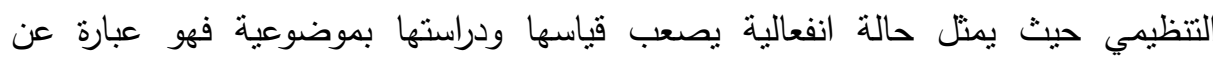
الاستجابات العاطفية التي تصدر عن الفرد تجاه جوانب عديده من عمله وتتشمل شعور العامل

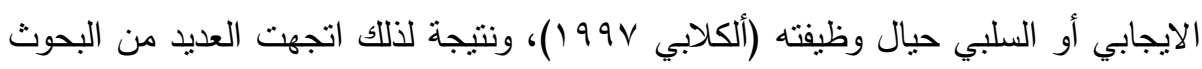
والدراسات إلى تتاوله إلا أنها لم تتقق على تعريف دقيق للرضا الوظيفى فتعددت النظريات 494

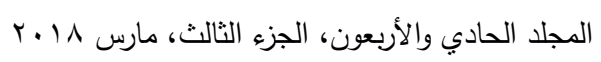


التي اهتمت بالرضا الوظيفي وقياسه علي مر العصور، فاللرضا الوظيفي جوانب متعددة ويعتمد علي محددات وعوامل تسهم في نكوين الرضا للفرد وتحديد مداه حيث تتقسم حسب نظريه الدافع إلي ما يلى:-

!. عوامل شخصية: تتعلق بقدرات ومهارت العاملين لمستوي الدافعية لديهم ونتشمل هذه

$$
\text { العوامل (المؤهل العلمي، فئات العمر ، الخبرة ومسنوي الطموح وغيرها). }
$$

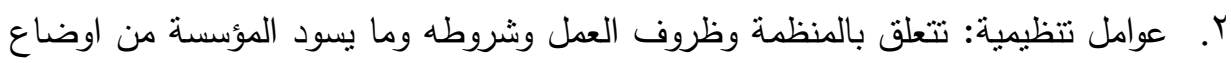
وعلاقات وظيفية ترتبط بالعاملين والوظيفة والعلاقة مع الزملاء والرؤساء ومستوي الوظيفة

$$
\text { ومحتواها ومسؤوليتها. }
$$

r. عوامل بيئية: مرتبطة بمحيط العمل وثأثنرها علي العامل وتثتمل المرافق والخدمات والتسهيلات المتوفرة بمكان ومحيط العمل، وتتشمل أيضا نظرة المجتمع إلي العاملين ومدي وليدي

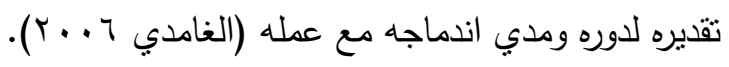

هذا ولا يمكن تجاهل البيئة الاجتماعية والاقتصادية التي تعمل فيها المنظمة عند دراسية الرضا الوظيفي للعاملين بهاحيث يؤدي التجاهل إلى تجاهل العمل لاى العاملين وزيادة الإحساس لديهم بالاغتراب والاحتقار، وعدم الانتماء والولاء. وعلى العكس فإن مراعاة البيئة تؤدى إلى الرضا عن محيط العمل، ومن ثم الرضا عن العمل نفسه مما يؤدي إلى تحسين اتجاهات العاملين بالمنظمة نحو الولاء والانتماء لها.

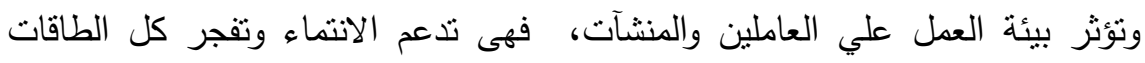
والقدرات من قبل العاملين للمنشأة عندما تقدم المنشأة البيئة المثالية للعمل والتى ترفع من أداء

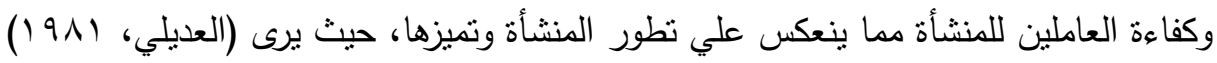

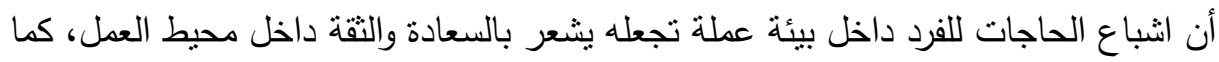
يري (عبد اللطيف، 997 (1) أن الانسان عبارة عن مجموعة من المشاعر التي تتبع نتيجة

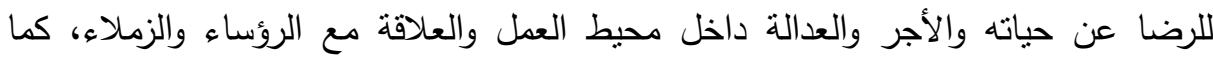

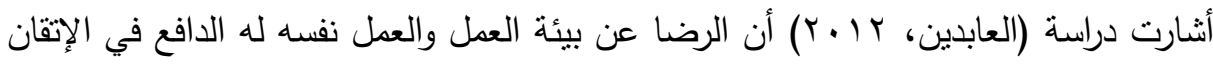

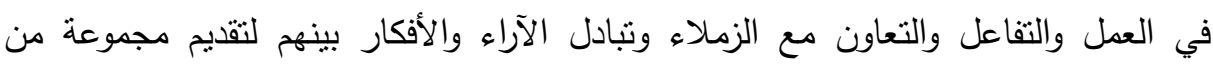

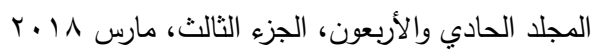


الأفكار لتطوير العمل والأداء وتقديم المساعدة في حل مشكلة معينة عن طريق الاتصال بين

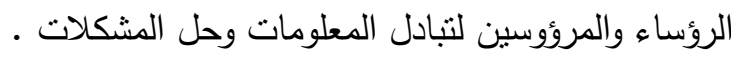

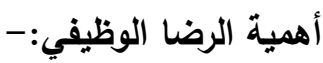

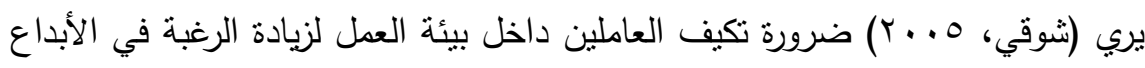
والأبنكار حيث أن تلبية احتباجات العاملين من حاجات مادية (أكل، شرب، سكن.....

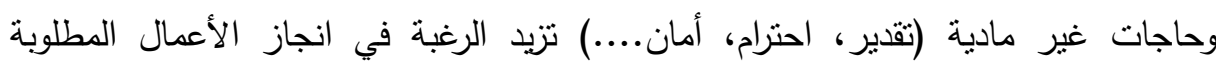

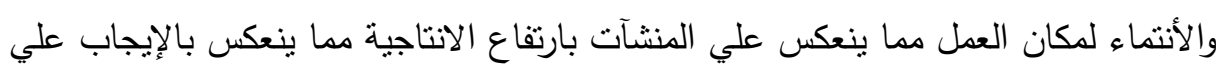

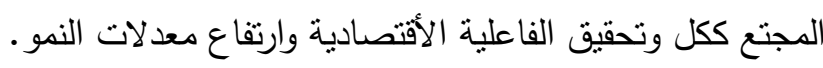

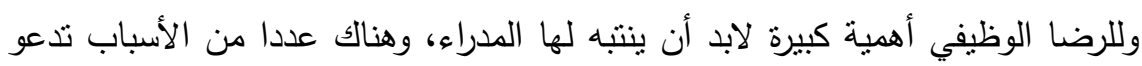

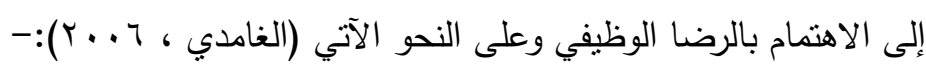

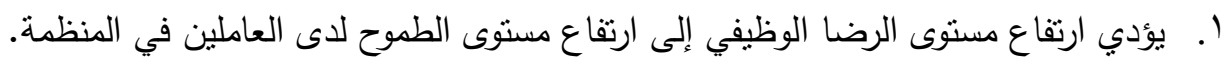
r. ب. بؤدي ارتفاع مستوى الرضا الوظيفي إلى انخفاض نسبة غياب العاملين في المنظمة.

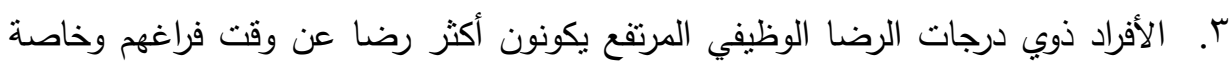
مع عائلاتهم وكنللك أكثر رضا عن الحياة بصفة عامة.

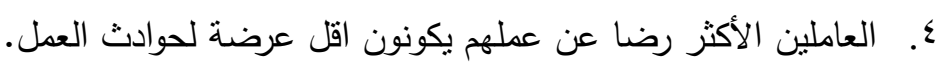
عوامل ومحددات الرضا الوظيفي:يحدد بعض الباحثين عوامل ومحدات الرضا الوظيفي كالاتي (ناصف عبد الخالق،

1- عوامل ذاتية تتعلق بقدرات ومؤهلات ومهارات العاملين.

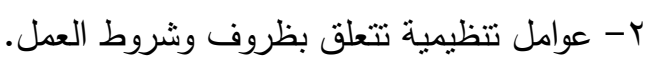

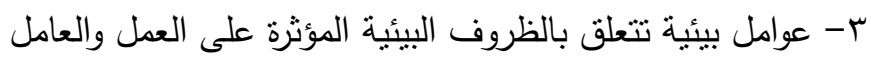

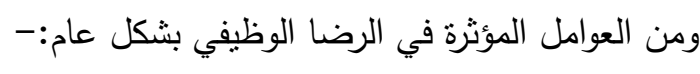
1-الرضا عن الوظيفة بشكل عام.

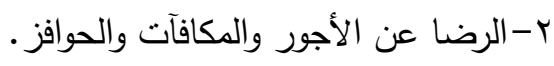




$$
\text { ع ז-الرضا عن النمو والإرتقاء الوظيفي. }
$$

ه-الرضا عن الثفافية والإتصال والتواصل بين القادة والموظفين.

$$
\text { 7-الرضا عن مجموعة العمل. }
$$$$
\text { V - الرضا عن النواحي الإجنماعية. }
$$

1- الرضا عن بيئة العمل المادية.

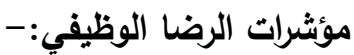

هناك مجموعة من المؤشرات التي تستخدم في حالة الرضا أو عدم الرضا لدي الأفراد

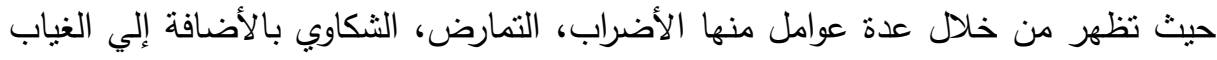

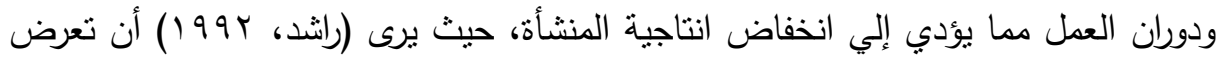
العاملين لضغوط عمل أقل غير كافية للحث علي العمل وبنيت الدراسة علي أن هنالك ثلاثة لثانة اتجاهات لمفهوم ضغوط العمل وأثاره الناتجة عنه (المثثير ، الاستجابة، والتفاعل).

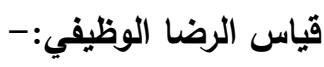

ان قياس الرضا الوظيفي يهم كل من علماء النفس والمدراء، فالكثير من القرارات الإدارية تفحص وتدرس حسب مدى نأثيرها على الرضا الوظيفي، وعليه فقد كان نظوير قياس الرضاء

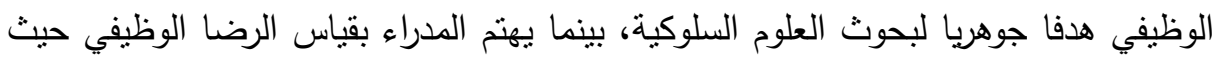
يعتبرونه مؤشرا للكفاءة التتظيمية. وهناك مجموعة من الطرق لقياس الرضا الوظيفي والتى منها ما يلى:-

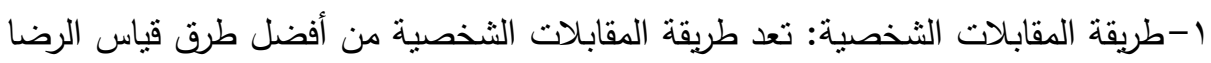
الوظيفي، وتتضمن مقابلة العاملين بصفة شخصية. r-طريقة رواية القصة: تستعمل لقياس رضا الأفراد لمعرفة مشاعرهم تجاه العمل، وقد توصلت هذه الطريقة إلى نتيجة هامة بأن العوامل التي يؤدي وجودها إلى الرضا لا يؤدي

$$
\text { غيابها إلى عدم الرضا. }
$$

r-طريقة الاستبيان: هذه الطريقة تتضمن توجيه عدد من الأسئلة ضمن استمارة تحتوبي على الى أبعاد الرضا الوظيفي، وتتلاءم مع مستويات أفراد عينة البحث.

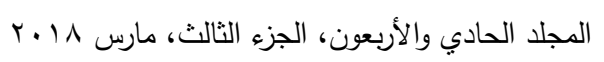




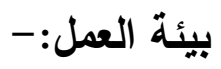

\section{مفهوم بيئة العمل:-}

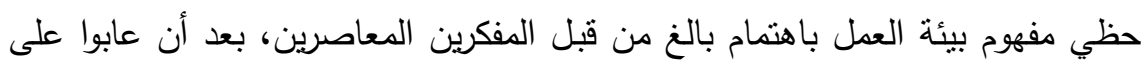

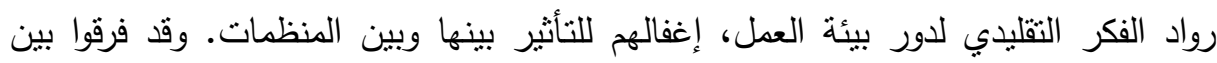
درجة الاهتمام بهذا التأثير في منظمات الأعمال، حيث يقل هذا الاهتمام نظراً لتركيز هذا لهني

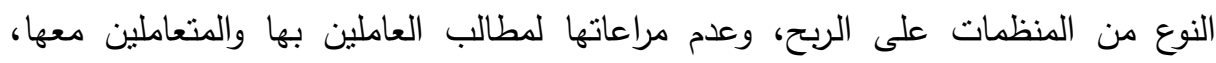
وبالتالي عدم تحسين علاقاتها بالبيئة المحيطة بها، وتعميق فهمها لمتغيراتها، خلاف

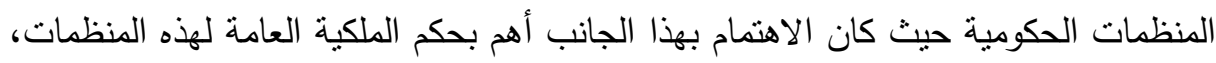

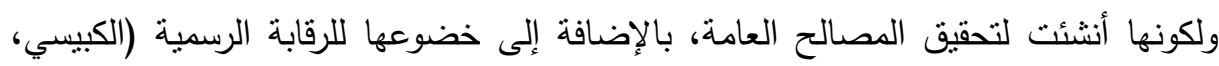

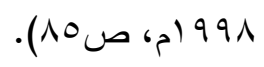

ونيجة لعلاقة بيئة العمل بالمناخ التنظيمي داخل المنظمة فقد ظهرت الكثير من

المصطلحات التي تعبر عن المناخ التتظيمي ورغم وجود بعض الاختلافات بين هذه المصطلحات إلا أنها مترابطة ومتداخلة واهنماماتها مشتركة بالظروف المتعلقة بالمنشأت ومحيطها التنظيمي وسلوك الفرد والجماعة، حيث عرف (العواملة، ؟99 1) المناخ التنظيمي بلهي

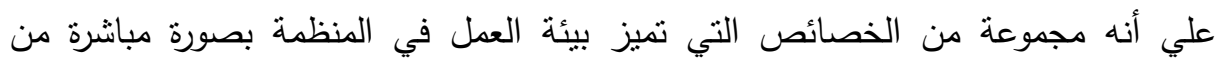
العاملين في تلاك البيئة والخصائص التي لها تأثير واضح علي دوافع وسلوكيات العاملين، كما لتائه

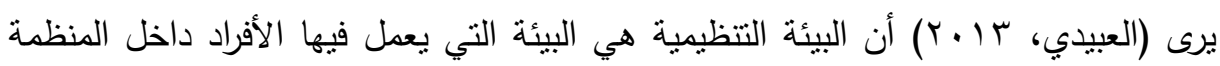

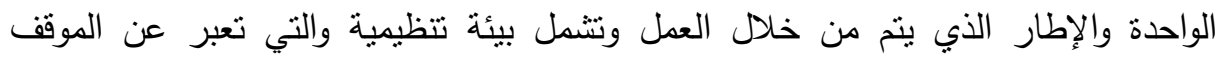
الاجتماعي والعلاقات بين الأفراد، والبيئة الوظيفية والتي تشمل مشاركة الأفراد في القرارات والأهداف الخاصة بالمنظمة وتوضح المسئوليات ورفع مستوي قدراتهم وابداعهم. أهمية دراسة المناخ التظظيمي:-

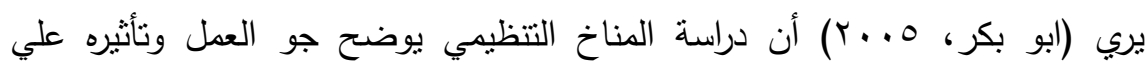

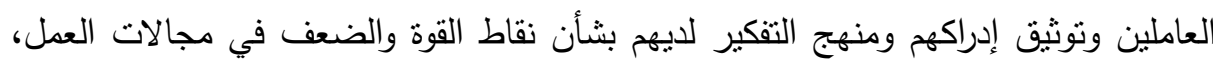

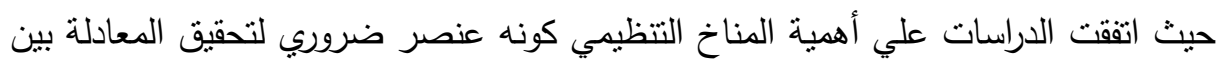

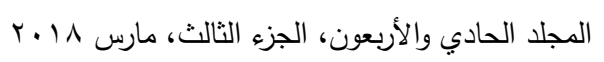


أهداف المنظمة وأهداف العاملين فالمناخ التنظيمي يعمل كوسيط بين متطلبات الوظيفة

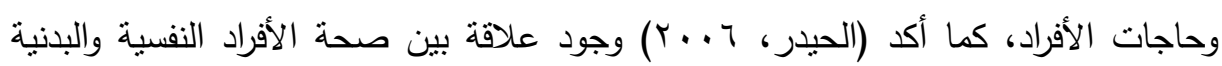

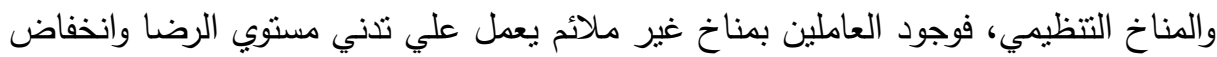

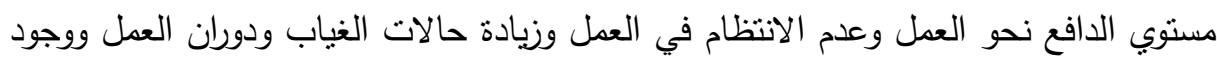
حالات التوتر وعدم الثقة والتعاون بين العاملين والإدارة مما يؤدي إلي انخفاض مستوي المنشأة وعدم تحقيق أهدافها.

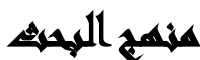

تعرض منهجية البحث النطبيقية كل من مجتمع وعينة البحث، مصادر جمع البيانات، فضلاً عن الأساليب الإحصائية المستخدمة في تحليل بيانات البحث.

$$
\text { مجتمع وعينة البحث:- }
$$

يتكون مجتمع الدراسة من كافة أعضاء هيئة التدريس بالجامعة المصرية، ونظراً لكبر

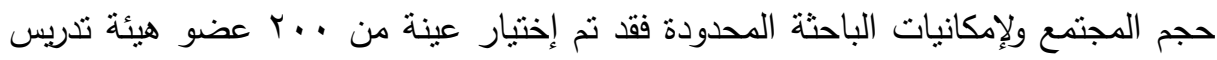

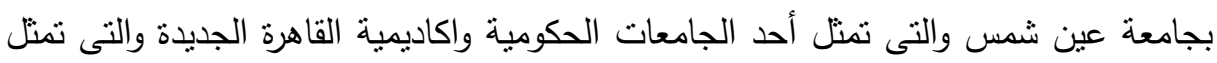
أحد مؤسسات التعليم الجامعى الخاص، ويمكن توضيح عدد الاسنبيانات الموزعة والصالحة للتحليل الاحصائى من خلال الجدول رقم (1) التالى:جدول (1): الاستبيانات الصالحة للتحليل

\begin{tabular}{|c|c|c|c|c|}
\hline النسبة & الاستبيانات الصالحة & الاستجابة & عدد الاستبيانات & الاستبيانات \\
\hline$\% \wedge \vee$ & $1 V \varepsilon$ & $\% q r, 0$ & 110 & r.. \\
\hline
\end{tabular}

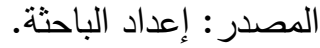
مصادر جمع البيانات:-

استخدت الباحثة الاستبيان كأداة لجمع المعلومات اللازمة لهذا البحث، وقد اعتمدت الباحثة في تصميم الاستبانة على مجموعة مقاييس جاهزة تم اعتمادها في دراسات وبحوث

$$
\text { المجلد الحادي والأربعون، الجزء الثالث، مارس 11 ـ }
$$


سابقة حول هذا الموضوع وتم اختبار وتحوير بعض الفقرات بما يتتاسب وبيئة العمل، حيث تم

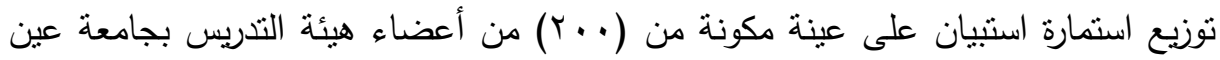

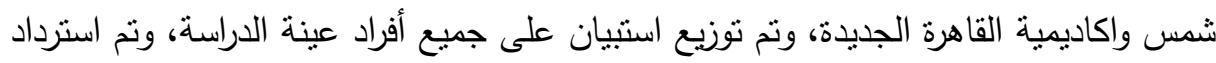

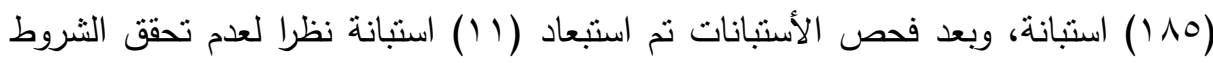
المطلوبة للإجابة على الاستبيان، وبذللك يكون عدد الاستبانات الخاضعة والصالحة للتحليل

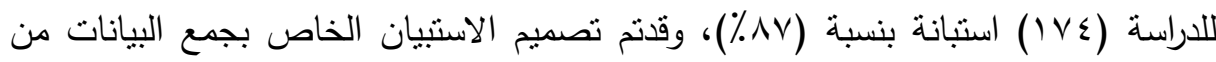
عينة الدراسة وفقا لمقياس ليكرت الخماسي وفقا للارجات التالية:جدول (r): درجات الاستبيان

\begin{tabular}{|c|c|c|c|c|c|}
\hline راض بشدة & راض & محايد & غير راضي & غير راض بشدة & التصنيف \\
\hline 0 & $\varepsilon$ & $r$ & r & 1 & الترميز \\
\hline
\end{tabular}

الأساليب الاحصائية المستخدمة فى تحليل بيانات البحث:-

تم اختبار مدى صحة فروض البحث التطبيقية اعتماداً على الأساليب الإحصائية التالية:!. اختبار كولومجروف سمرنوف، واختبار شابيرو لفحص مدى تبعية البيانات للتوزيع الطبيعى.

r. ت تحليل الارتباط لتحديد اتجاهوقوة العلاقة بين الرضا الوظيفى وبيئة العمل.

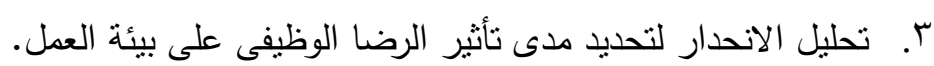

\section{تحليل نتائي المهيث}

قام البحث بتوظيف البيانات التى نم الحصول عليها بهدف تحديد العلاقة بين الرضا الوظيفى وبيئة العمل، فضلاً عن تحديد مدى نأثير الرضا الوظيفى على بيئة العمل لأعضاء هيئة التدريس بالجامعات المصرية، وقد اعتمدت الدراسة على استخدام الأساليب الإحصائية

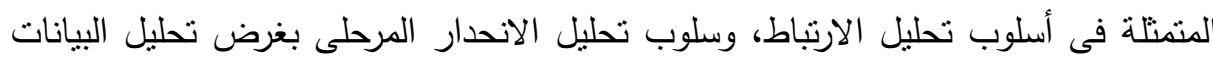
واختبار مدى صحة فروض البحث واستخلاص نتائجها، ويمكن نوضيح ذلك كما يلى:- 


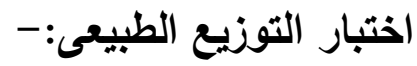

لفحص مدى تبعية متغيرات البحث للتوزيع الطبيعى فقد اعتمد البحث على كل من

اختبار Kolmogorov-Smirnov، واختبار Shapiro-Wilk حيث نتبع المتغيرات التوزيع

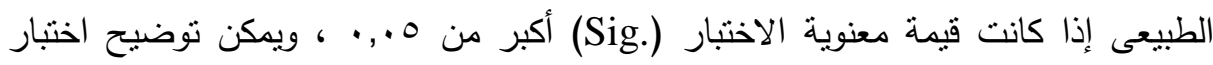

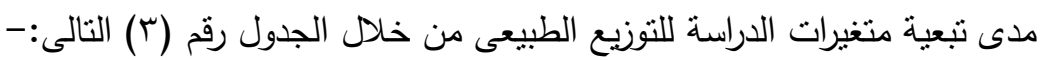
جدول (ץ) : Tests of Normality

\begin{tabular}{|c|c|c|c|c|c|c|}
\hline \multirow{2}{*}{ No. } & \multicolumn{3}{|c|}{ Kolmogorov-Smirnova } & \multicolumn{3}{|c|}{ Shapiro-Wilk } \\
\hline & Statistic & df & Sig. & Statistic & df & Sig. \\
\hline س - س & .303 & 174 & .000 & .775 & 174 & .000 \\
\hline 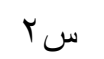 & .407 & 174 & .000 & .305 & 174 & .000 \\
\hline س & .310 & 174 & .000 & .820 & 174 & .000 \\
\hline 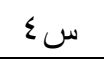 & .314 & 174 & .000 & .797 & 174 & .000 \\
\hline س & .318 & 174 & .000 & .784 & 174 & .000 \\
\hline سل & .283 & 174 & .000 & .838 & 174 & .000 \\
\hline 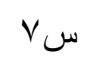 & .279 & 174 & .000 & .839 & 174 & .000 \\
\hline سـ & .280 & 174 & .000 & .823 & 174 & .000 \\
\hline س & .235 & 174 & .000 & .876 & 174 & .000 \\
\hline س. & .218 & 174 & .000 & .863 & 174 & .000 \\
\hline س & .285 & 174 & .000 & .717 & 174 & .000 \\
\hline سri & .284 & 174 & .000 & .728 & 174 & .000 \\
\hline سזו & .270 & 174 & .000 & .751 & 174 & .000 \\
\hline سع & .282 & 174 & .000 & .720 & 174 & .000 \\
\hline س10 & .283 & 174 & .000 & .709 & 174 & .000 \\
\hline س71 & .262 & 174 & .000 & .761 & 174 & .000 \\
\hline
\end{tabular}


تابع جدول (ّ): Tests of Normality

\begin{tabular}{|c|c|c|c|c|c|c|}
\hline \multirow{2}{*}{ No. } & \multicolumn{3}{|c|}{ Kolmogorov-Smirnova } & \multicolumn{3}{|c|}{ Shapiro-Wilk } \\
\hline & Statistic & df & Sig. & Statistic & df & Sig. \\
\hline س & .279 & 174 & .000 & .727 & 174 & .000 \\
\hline سم1 & .322 & 174 & .000 & .679 & 174 & .000 \\
\hline (19 & .285 & 174 & .000 & .702 & 174 & .000 \\
\hline س. & .324 & 174 & .000 & .694 & 174 & .000 \\
\hline س r & .272 & 174 & .000 & .769 & 174 & .000 \\
\hline س & .250 & 174 & .000 & .789 & 174 & .000 \\
\hline س & .287 & 174 & .000 & .776 & 174 & .000 \\
\hline س & .292 & 174 & .000 & .758 & 174 & .000 \\
\hline سمr & .288 & 174 & .000 & .773 & 174 & .000 \\
\hline س ( & .293 & 174 & .000 & .757 & 174 & .000 \\
\hline T & .299 & 174 & .000 & .757 & 174 & .000 \\
\hline 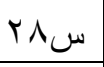 & .266 & 174 & .000 & .739 & 174 & .000 \\
\hline سوب & .287 & 174 & .000 & .750 & 174 & .000 \\
\hline س.r & .295 & 174 & .000 & .732 & 174 & .000 \\
\hline س آ & .303 & 174 & .000 & .684 & 174 & .000 \\
\hline
\end{tabular}

Kolmogorov- بفص نتائج الجدول رقم (r) لوحظ أن قيمة المعنوية لكل من اختبار Smirnov، واختبار Shapiro-Wilk أقل من (0.,.) مما يشير إلى عدم اقتراب متغيرات البحث من التوزيع الطبيعى، وعليه سوف تستخدم الطرق اللامعلمية في اختبار الفروض.

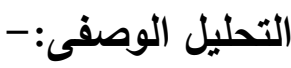

اعتمد البحث فى التحليل الوصفى على الوسط الحسابى والاتحراف المعيارى، ويمكن توضيح ذللك كما يلى:- 
محمد عبد العزيز وآخرون

\section{توزيع افراد مجتمع البحث وفقا للخدمة في الجامعة:-}

اعتمد البحث فى تحديد سنوات الخبرة لأفراد العينة في مجال التدريس الجامعي على لجى

التكرارات والنسب المئوية، ويمكن نوضيح ذلك من خلال الجدول رقم (ع) التالي:-

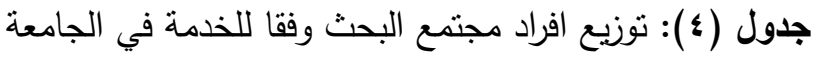

\begin{tabular}{|c|c|c|}
\hline النسبـــة \% & التكــرار & مـــــة الخــــــــــة \\
\hline $1 \cdot 6$ & 11 & أقل من ه سنوات \\
\hline$r V_{6} 0$ & $\leqslant \wedge$ & من ه سنوات إلى أقل من · ( سنوات \\
\hline 0161 & 19 & من · ا سنوات إلى أقل من · r سنة \\
\hline 1.69 & 19 & من •r سنة فأكـثر \\
\hline $1 \ldots$ & $\mid V \varepsilon$ & المجموع \\
\hline
\end{tabular}

المصدر : نتائج التحليل الإحصائى.

بفص بيانات الجدول رقم (ع) تري الباحثة ان اغلب افراد العينة لدية سنوات خبرة

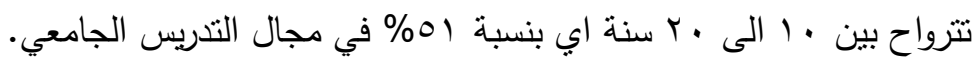
خصائص عينة الاراسة: -

اعتمد البحث فى تحديد الخصائص الديموغرافية لأفراد العينة على التكرارات والنسب

المئوية، ويمكن توضيح ذلك من خلال الجدول رقم (0) التالى:- 
مجلة العلوم البيئية

معهز الدراسات والبحوث البيئية - جامعة عين شمس لهن

جدول (•): التكرارات والنسب المئوية لعينة البحث حسب المتغيرات الديموغرافية

\begin{tabular}{|c|c|c|c|}
\hline النسبة \% & التكرار & الفئات & المتغير \\
\hline $0 \wedge, 7$ & $1 \cdot r$ & ذكر & \multirow{2}{*}{ الجنس } \\
\hline$\varepsilon 1, \varepsilon$ & VY & أنثي & \\
\hline$r 4, \Lambda$ & $7 \varepsilon$ & هو - & \multirow{4}{*}{ العمر } \\
\hline 10,0 & TV & •r-q سنة & \\
\hline M & $0 \leqslant$ & $\varepsilon q-\varepsilon$. & \\
\hline $17, V$ & rq & • 0 سنة فأكثر & \\
\hline $1 \wedge, \varepsilon$ & rt & بكالوربوس & \multirow{3}{*}{ المؤهل العلمي } \\
\hline TE & 09 & ماجستير & \\
\hline$\varepsilon \vee, V$ & $\Lambda r$ & دكتوراه & \\
\hline $1 \wedge, \varepsilon$ & r & معيد & \multirow{5}{*}{ الدرجة العلمية } \\
\hline rక & 09 & مدرس مساعد & \\
\hline $1 Y, 7$ & rY & مدرس & \\
\hline$r), r$ & rv & استاذ مساعد & \\
\hline $1 \pi, \Lambda$ & $r \varepsilon$ & استاذ & \\
\hline $1 \cdots$, & IVE & المجموع & \\
\hline
\end{tabular}

المصدر : نتائج التحليل الإحصائى

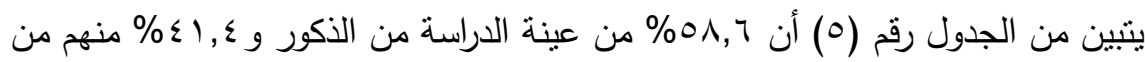

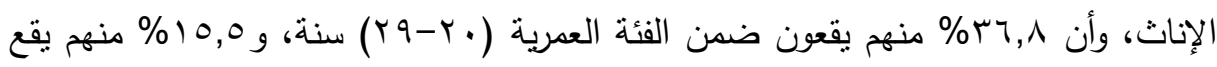

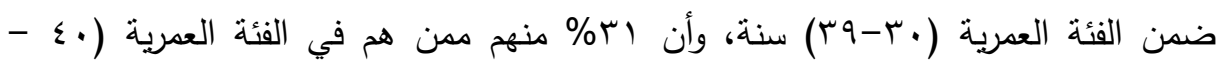

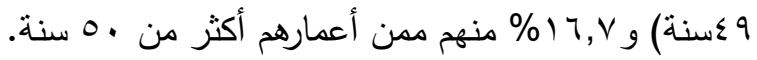
الأهمية النسبية لبيئة العمل:-

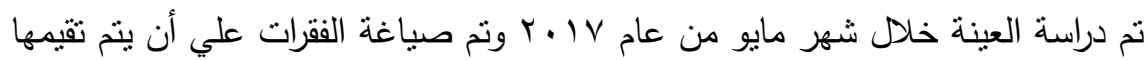
بعبارات موافق بشدة، موافق، إلي حد ما، غير موافق، غير موافق بشدة، كما هو موضح

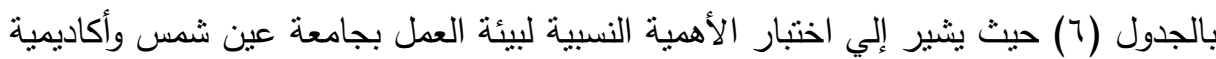
القاهرة الجديدة لحساب الوسط الحسابي والانحراف المعياري لكل فقرة من فقرات بيئة العمل 
وكانت النتائج تكثف عن عدم وجود رضا بالقطاعين حيث تم الموافقة علي معظم الفقرات بالرفض ويظهر ذلك في ارتفاع قيمة الوسط الحسابي (أكبر من بم). جدول (†): الأهمية النسبية لبيئة العمل

\begin{tabular}{|c|c|c|c|}
\hline المعياربي & الحسابي & 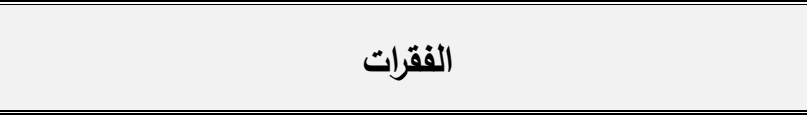 & b \\
\hline $1, .1 \leq$ & $r, \varepsilon$. & هل ظروف العمل مريحة وتساعد علي التقدم والإنجاز ؟ & 111 \\
\hline $1,1 \ldots$ & r,々० & هل يتوفر داخل مكان عملك مكاتب مناسبة وخاصة لكل فرد؟ & MII \\
\hline $1, r \wedge 9$ & r,. . & هل يتوفر داخل مكان العمل عدد كاف من أجهزة الحاسب & MI \\
\hline $1, \leqslant 1$. & r,qV & هل الأجهزة مزودة بشبكة الأنترنت والبرامج المتخصصة ؟ & हा \\
\hline
\end{tabular}
المصدر : نتائج التحليل الإحصائى.

باسنقراء بيانات الجدول رقم (؟) لوحظ انخفاض الأهمية النسبية لبيئة العمل حيث كانت استجابات أفراد العينة منخفض مما يثير إلى عدم الرضا عن مكان العمل من حيث أجهزة

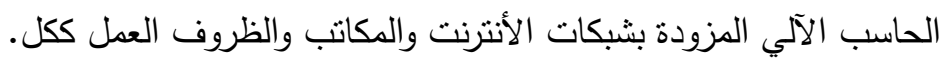
تحليل العلاقة بين الرضا الوظيفى وييئة العمل:-

لتحليل علاقة الارتباط وتقدير المساهمة النسبية بين الرضا الوظيفى وبيئة العمل، يتم

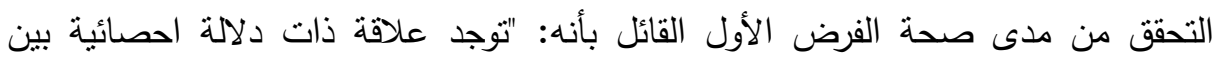

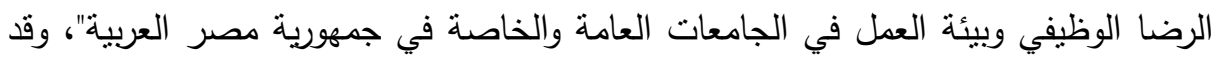

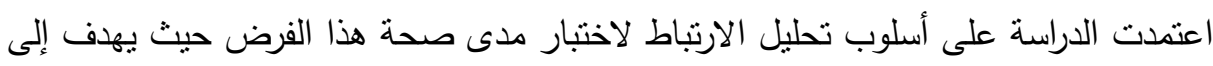

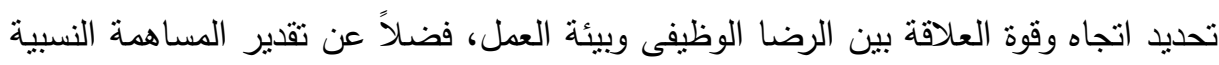

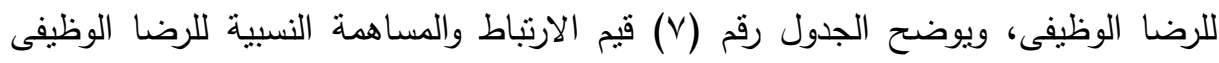

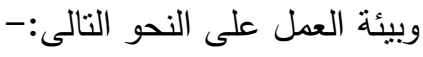

جدول (V): معامل الارنباط بين احتياجات العاملين والرضا الوظيفي

\begin{tabular}{|c|c|c|c|}
\hline \multicolumn{2}{|c|}{ معامل الأرتباط } & المتغير التابع & لمتغير المستقل \\
\hline المعنوية & القيمة & & \\
\hline,$\ldots$ &., 09. & & الوظيهي \\
\hline
\end{tabular}

الصصدر : نتائج التحليل الإحصائى.

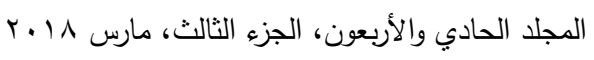


بفحص بيانات الجدول رقم (V) لوحظ وجود علاقة ارتباط معنوية طردية بين الرضا

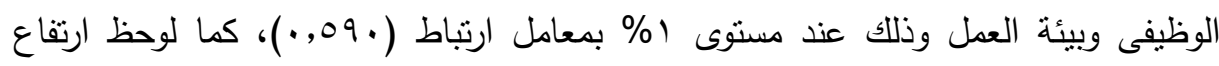

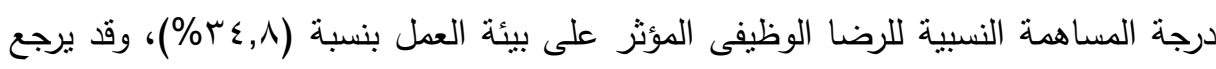

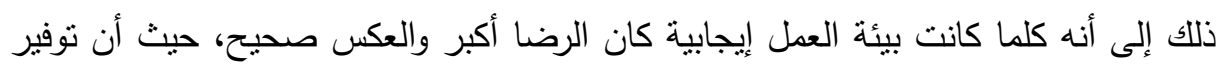

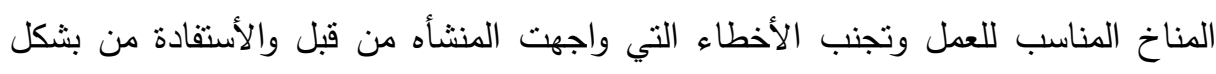
كبير من أراء العاملين ودراسة نقاط القوة والضعف تجعل لدي الافراد القناعة بحب المكان والأنتماء لبيئة العمل والقدرة علي التطوير والأبتكار .

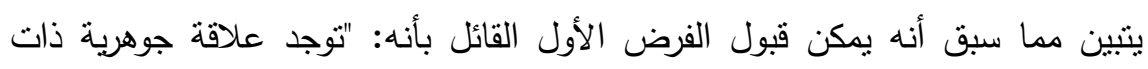

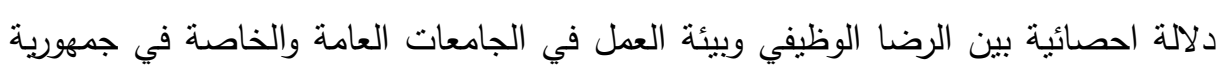

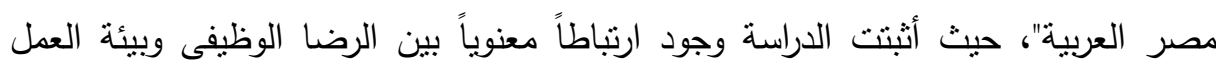
وذللك عند مستوى /\% مما يشير إلى أهمية الاعتماد على الرضا الوظيفى فى تقدير بيئة العمل بدقة عالية. اختبار مدى تأثير الرضا الوظيفى على بيئة العمل:-

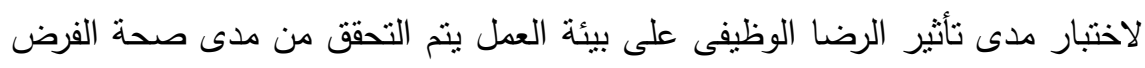

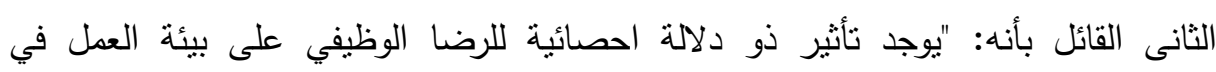

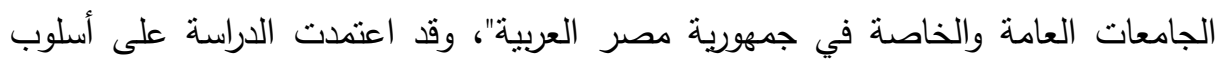

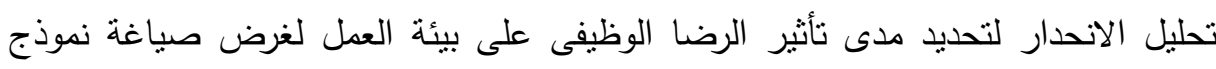

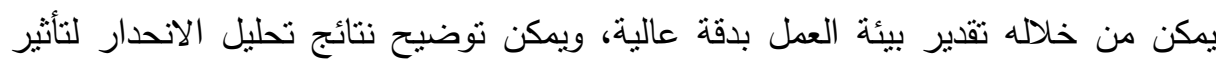
الرضا الوظيفى على بيئة العمل من خلال الجدول رقم (^) التالي:- 
محمد عبد العزيز وآخرون

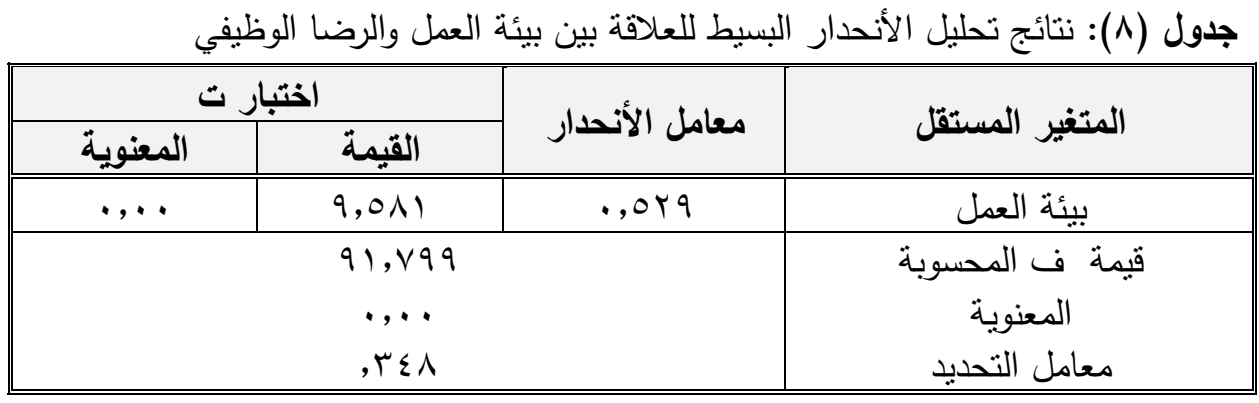

المصدر : نتائج التحليل الإحصائى.

بفحص بيانات الجدول رقم (^) لوحظ وجود تأثثر معنوى للرضا الوظيفي في النجاح

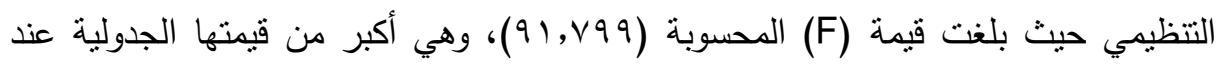

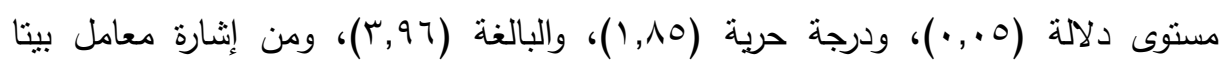

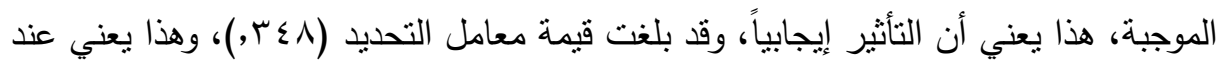

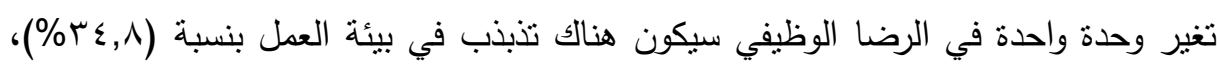

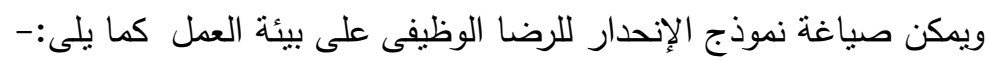
$Y=9.581+0.529 X_{1}$ حيث أن:

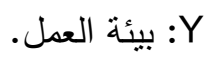
X1

يتضح مما سبق أنه يمكن قبول الفرض الثانى القائل بأنه "يوجد تأثير ذو دلالة احصائية

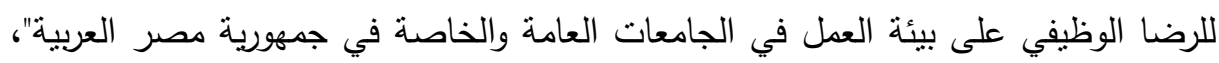
حيث أثتتت الدراسة وجود تأثير للرضا الوظيفى على بيئة العمل وبالتالى يمكن الاعتماد عليه فى تقدير بيئة العمل.

\section{المخالجمايتي}

أنثارت النتائج بالبحث أن هناك علاقة طردية بين بيئة العمل والرضا الوظيفي حيث

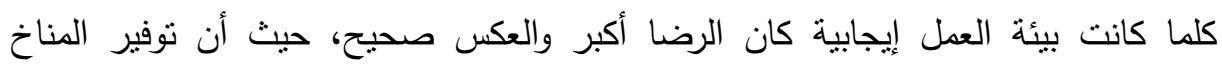

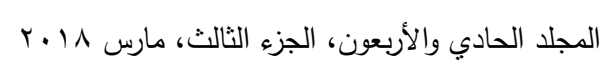


المناسب للعمل وتجنب الأخطاء التي واجهت المنشأه من قبل والأستفادة من بشكل كبير من أراء العاملين ودراسة نقاط القوة والضعف تجعل لدي الافراد القناعة بحب المكان والأنتماء لبيئة العمل والقدرة علي التطوبر والأبتكار ، ولايوجد اختلاف في الرضا عن بيئة العمل أو أولاء

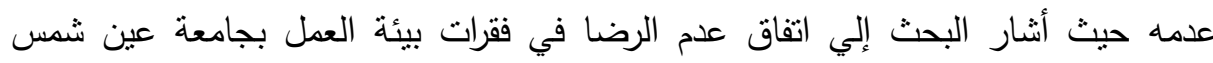
وأكادمية القاهرة الجديدة، أي أن الرضا عن مكان العمل لايختلف من مكان لآخر وعلي ذلك

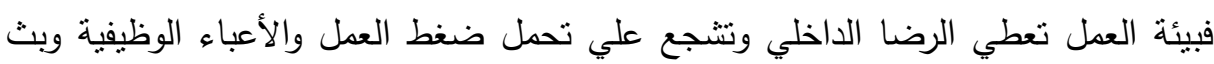
الراحة النفسية بالعاملين.

فتوفير سبل الراحة للعاملين وتذليل كل الصعاب التي تواجههم في أداء أعمالهم اليومية يؤدي إلي الحصول علي أفضل نتيجة وأعلي قدر من الأنجاز والفرصة لكتشاف قدئ قدرات ومواهب كل فرد من العاملين، لذلك ينصح بتحسين بيئة العمل الداخلية وتزويدها بمنطلبات

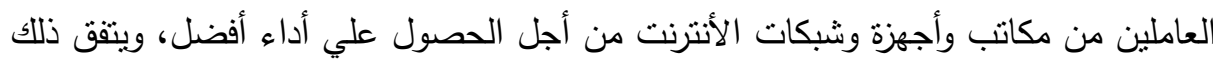

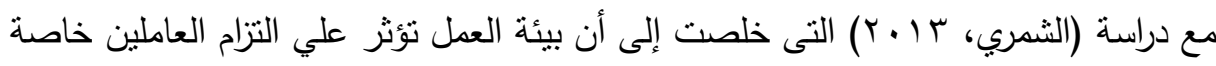
عند توفير مقومات البيئة المادية التي توفر الراحة والهدوء للعاملين والمساعدة علي التركيز

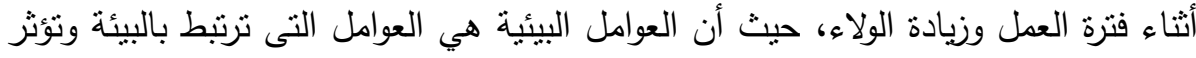

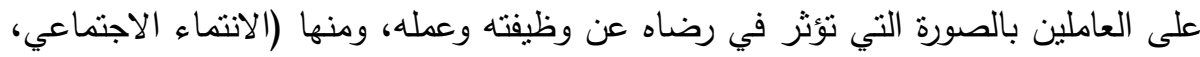
والانتماء البيئي لبعض العاملين إلى الريف أو المدينة) ولها أثر واضح على ولى درجة ولثة التكيف

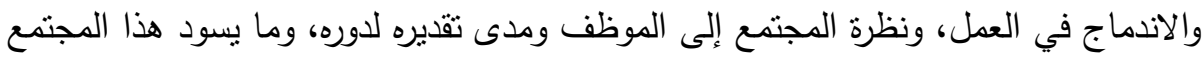
من أوضاع بمؤسساته ونظمه وقيمه، كل ذللك يعكس تأثنيره إيجابيا وسلبيا على اندماج الموظف وتكامله مع وظيفته.

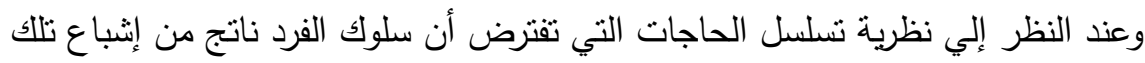
الحاجات وهي منسلسلة الي خمس نقاط بناء علي أهميتها التى تتمنل فى حاجات فيزيولوجية، الحاجة للأمن والأستقرار، حاجات أجتماعية كالصداقة والانتماء، حاجات خاصة بأهاء بالتقدير والثقة والأحترام والحاجة إلى تحقيق الذات من ابتكار وابداع (حسن، ع ـ . ب). 
ويمكن توضيح التسلسل الهرمي للحاجات وفقاً لماسلو من خلال الثكل رقم (1) التالى:-

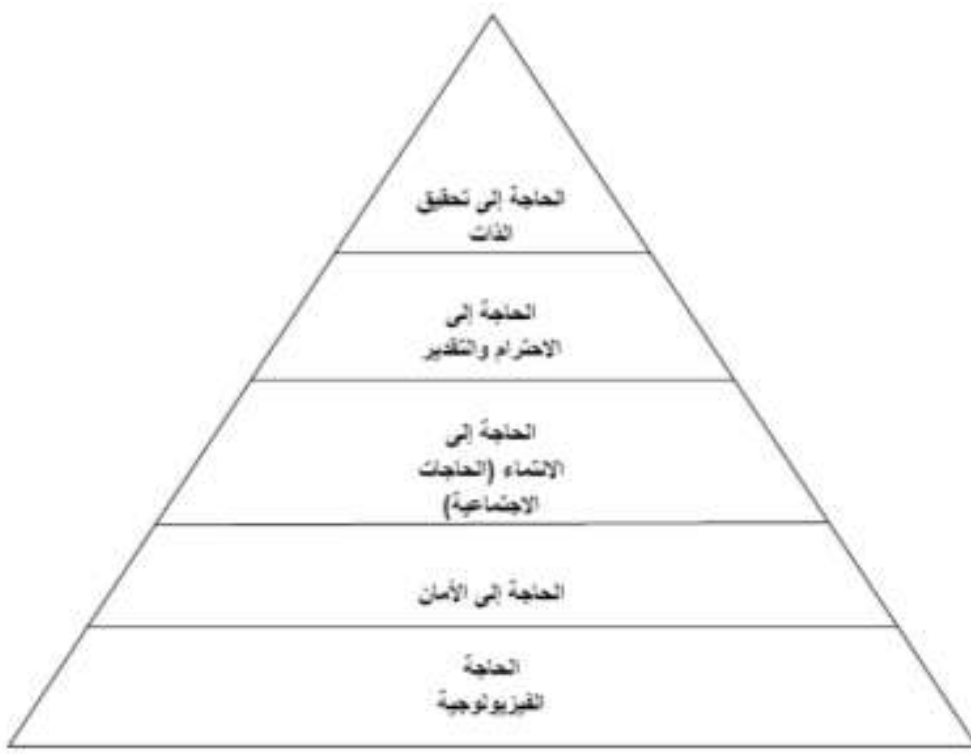

شكل (1): يوضح التسلسل الهرمي للحاجات وفقا لماسلو

هذا وتؤكد دراسات ماسلو أن الإحساس بالرضا لاى العاملين لا يمكن تحقيقه دون

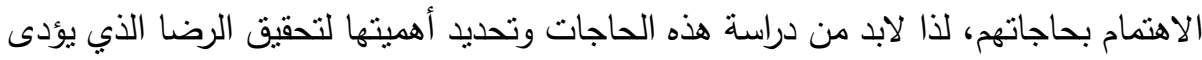
دور كبير في زيادة فعالية أداء العاملين والمنظمات وهذا من خلال تحفيز العاملين وإشعارهم بالأمن والاستقرار من خلال إثباع حاجاتهم.

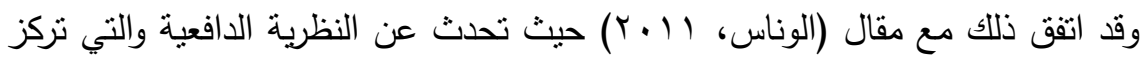
علي إنباع تحقيق الذات والإنجاز العملي وإرتباطها بعوامل صحية، وأن الظروف المحيطة

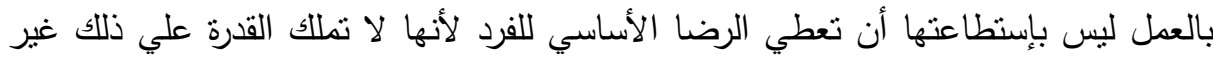

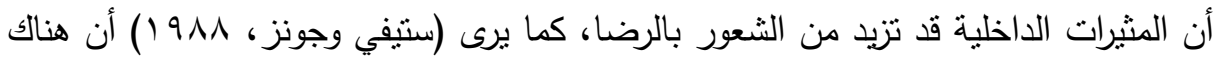
علاقة بين ضغوط العمل والرضا الوظيفي وهي علاقة إيجابية تؤثر علي انتاجية العمل. من خلال الاستعراض السريع لدفهوم الرضا الوظيفي وعلاقتة مع بيئة العمل بمكننا

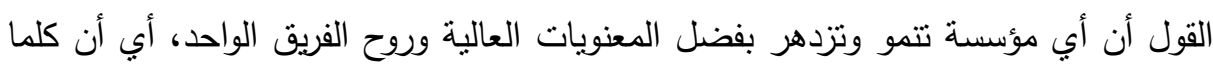

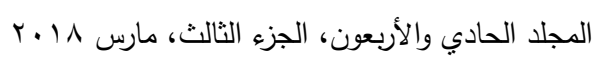


ارتفع مستوي بيئة العمل كلما ارتفع معدل الرضا الوظيفي لاي العمالين، فيجب العمل على تطوير مكان العمل وتزويده بإحتياجات العاملين من أجززة، مكاتب، تهوية وراحة نفسية العندية للأرتقاء بمستوي العمل وزيادة الرضا الوظيفي. فالمرنب المغري أو المكافأت نساعد العاملين

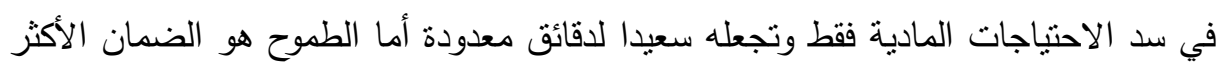

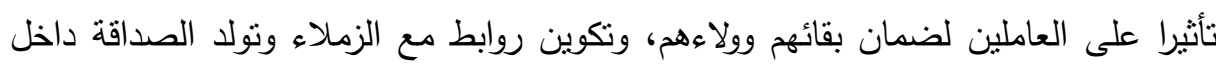

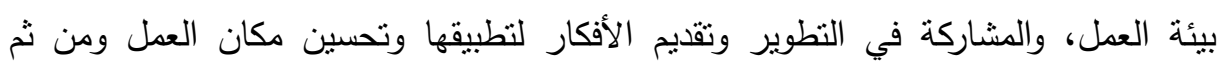

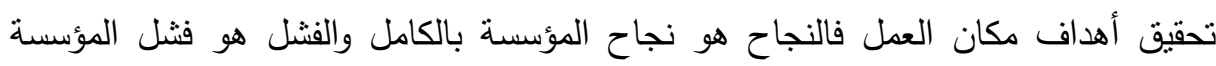
بالكامل، وعلينا توفير كل احتباجات العاملين لكي نسير معهم في طريق النجاح.

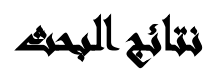

خلص البحث إلى مجموعة من النتائج يمكن تتاولها على النحو التالى:-

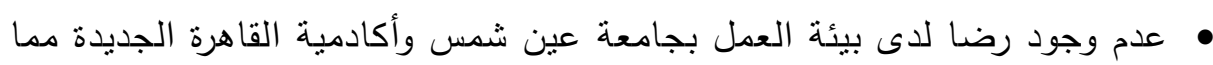
يشير إلى أن الرضا عن مكان العمل لا يختلف من مكان لآخر وعلي ذلك فبيئة

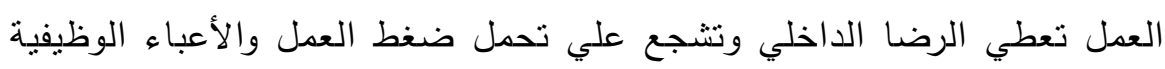
وبث الراحة النفسية بالعاملين.

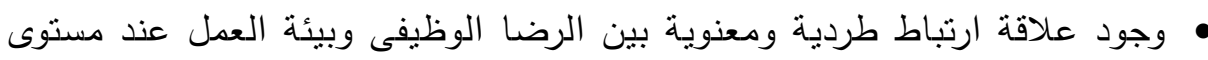

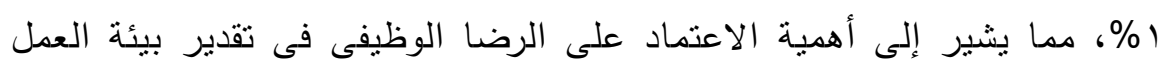
بدقة عالية. • امكانية تقدير بيئة العمل اعتماداً على الرضا الوظيفى حيث بلغت قيمة معامل التحديد (م, ؟ \%).

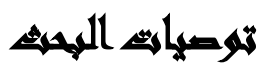

فى ضوء النتائج التى توصل إليها البحث فإنه يمكن تقديم مجموعة من التوصيات النالية:- 
• ضرورة العمل علي تطوير مكان العمل وتزويده باحتباجات العاملين من أجهزة، مكاتب، تهوية وراحة نفسية للأرتقاء بمستوي العمل وزيادة الرضا الوظيف لونيفي.

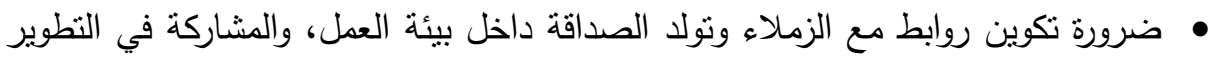
وتقديم الأفكار لتطبيقها وتحسين مكان العمل مما يؤدى إلى تحقيق أهداف مكان العمل

$$
\text { وما يستتبعه من نجاح المؤسسة بالكامل. }
$$

• ضرورة تحسين بيئة العمل الداخلية وتزويدها بمنطلبات العاملين من مكاتب وأجهزة

$$
\text { وشبكات الأنترنت بغرض الحصول علي آداء أفضل. }
$$

\section{المرالية}

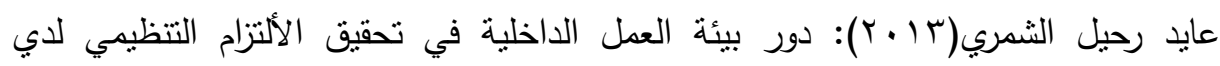

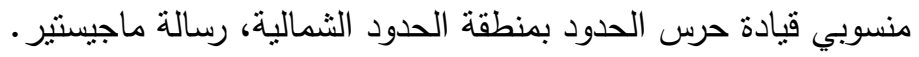

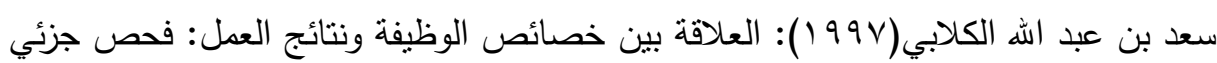

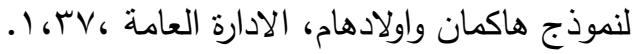

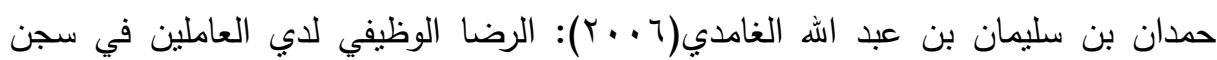

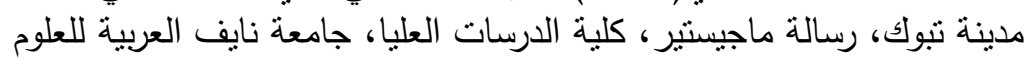

$$
\text { الأمنية. }
$$

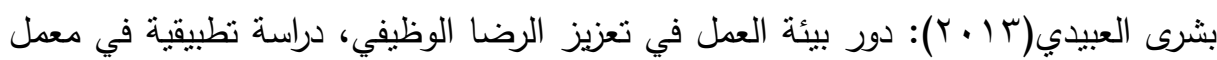
بغداد للغاز ، مجلة كلية العلوم الأقتصادية، العدد السادس والثنلاثون.

سليمان أبو بكر (0 ب): التضارب التتظيمي والولاء في الثركات السودانية، رسالة ماجيستير غير منشورة، الجامعه الأردنية، عمان.

عبد المحسن بن صالح الحيدر: "اتجاهات العاملين نحو المناخ التنظمي وعلاقة خصائصهم

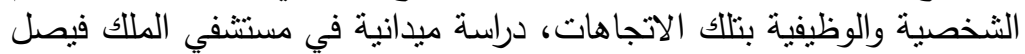

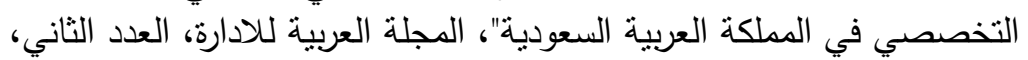

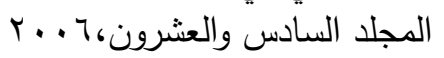

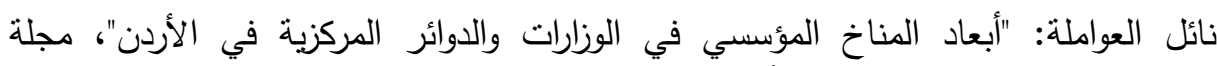

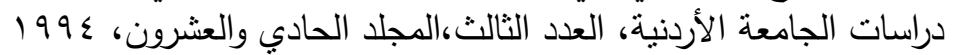

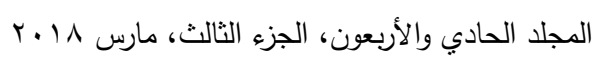


مجلة العلوم البيئية

معهد الدراسات والبحوث البيئية - جامعة عين شمس

ناصر العديلي(1911): الرضا الوظيفي دراسة ميدانية بإتجاهات ومواقف موظفي الأجهزة الحكومي في مدينة الرياض، رسالة ماجستير منشورة.

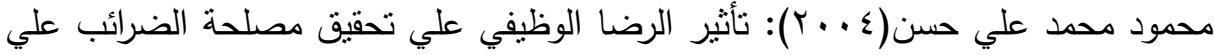

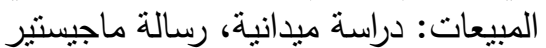

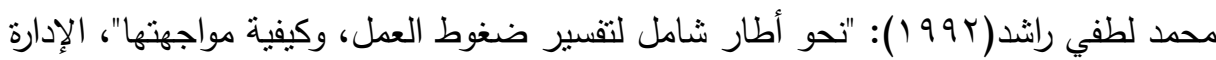

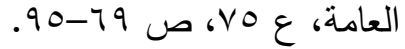

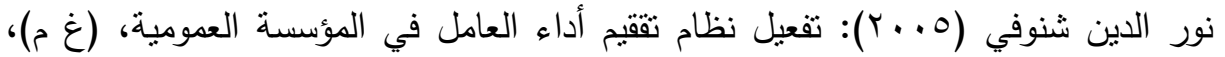
جامعة الجزائر.

محمد أمين عبد اللطيف(997 (1)): الإتنماء التتظيمي وعلاقته بالرضا الوظيفي والأداء

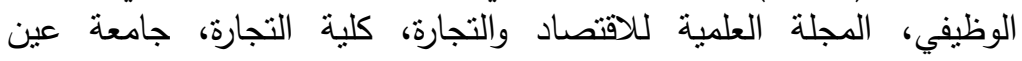

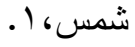

أحمد صقر عاشور (ب1911): إدارة الموارد البشرية، دار المعرفة الجامعية، الأسكندرية، مصر • مزياني وناس(1) ( ب): محددات الرضا الوظيفي وأثنارة علي المؤسسات في ظل النظريات المعرفية والسلوكية، مجلة العلوم الأنسانية والأجتماعية، جامعة قاصنية فاليد رماح،

$$
\text { . YYT-Y.96 } r
$$

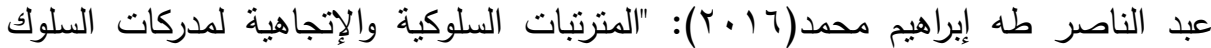

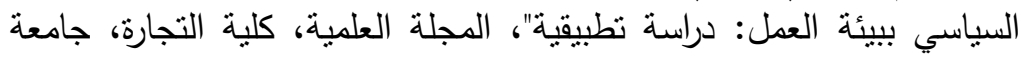

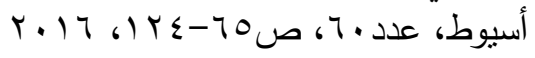

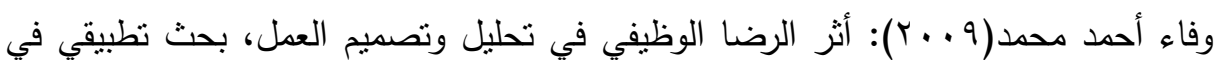

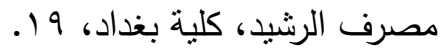

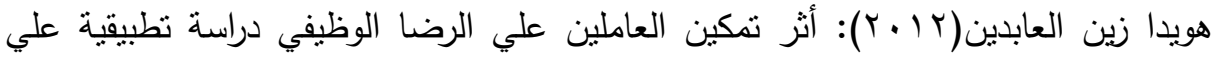
الجامعات المصرية الحكومية والخاصة، رسالة ماجيستير ، جامعة بني سويف.

Arne Speerforck \& Nicole Franzis--ka Richter (2014): International Differences in the Importance of Antecedents to Job Satisfaction and the Role of Socio-Economic Characteristics.

Chadi, A. \& Hetschko, C. (2018): The magic of the new: How job changes affect job satisfaction. Journal of Economics \& Management Strategy. 27(1), pp. 23-39.

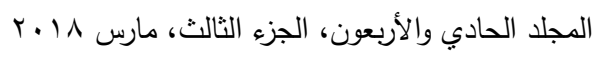


محمد عبد العزيز وآخرون

Cherian, S.; Al-khatib, A. J. \& Aggarwal, M. (2018): Relationship Between Organizational Commitment and Job Satisfaction of Nurses in Dubai Hospital. Journal of Advances in Social Science and Humanities, 4(1).

Estimo, E. T. \& Aguilar, G. M. (2017): Understanding Employees' Preferences: Their Work Values, Environment, Interaction and Activities. Science Journal of Education, 5(6), 236.

Goetz, K.; Kleine-Budde, K.; Bramesfeld, A. \& Stegbauer, C. (2018): Working atmosphere, job satisfaction and individual characteristics of community mental health professionals in integrated care. Health \& social care in the community, 26(2), 176-181.

Marques, C. P.; Leal, C. T.; Marques, C. S. \& Cabral, B. T. (2018): Internal marketing and job satisfaction in hotels in Via Costeira, Natal, Brazil. Tourism \& Management Studies, 14(1), 36-42.

Otterbring, T.; Pareigis, J.; Wästlund, E.; Makrygiannis, A. \& Lindström, A. (2018): The relationship between office type and job satisfaction: Testing a multiple mediation model through ease of interaction and well-being. Scandinavian journal of work, environment \& health.

Review of Integrated Business and Economics Research, Vol. 3, Issue 1, pp. 130-149.

Ristic, M. R.; Selakovic, M. \& Qureshi, T. M. (2017): Employee motivation strategies and creation of supportive work environment in societies of post-socialist transformation. Polish Journal of Management Studies, 15.

Sari, R. L. \& Seniati, A. N. L. (2018): The role of professional commitment as a mediator in the relationship between job satisfaction and organizational commitment among lecturers in higher-education institutions. Diversity in Unity: Perspectives from Psychology and Behavioral Sciences.

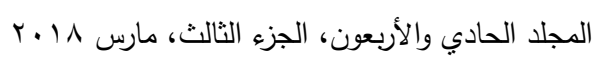




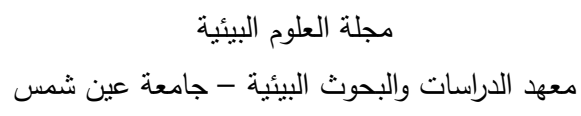

Shuck, B.; Peyton Roberts, T. \& Zigarmi, D. (2018): Employee Perceptions of the Work Environment, Motivational Outlooks, and Employee Work Intentions: An HR Practitioner's Dream or Nightmare?. Advances in Developing Human Resources.

Tasneem, S.; Cagatan, A. S.; Avci, M. Z. \& Basustaoglu, A. C. (2018): Job Satisfaction of Health Service Providers Working in a Public Tertiary Care Hospital of Pakistan. The Open Public Health Journal, 11(1).

Wan, Q.; Li, Z.; Zhou, W. \& Shang, S. (2018): Effects of work environment and job characteristics on the turnover intention of experienced nurses: The mediating role of work engagement. Journal of advanced nursing.

Yuena., K. F.; Hui Shan Lohb; Qingji Zhouc \& Yiik Diew Wongc (2018): Determinants of job satisfaction and performance of seafarers, Transportation Research Part A 110 (2018) 1-12.

Yeh, S. S.; \& Huan, T. C. (2017): Assessing the impact of work environment factors on employee creative performance of fine-dining restaurants. Tourism Management, 58, 119-131. 
محمد عبد العزيز وآخرون

\title{
JOB SATISFACTION AND ITS RELATION TO WORK ENVIRONMENT
}

\author{
Khalifa, M. A. ${ }^{(1)}$; Alber, $\mathrm{N}^{(1)}$ and Ibrahim, Soha \\ 1) Faculty of Commerce, Ain Shams University
}

[20]

\begin{abstract}
Job satisfaction is a sensory reaction to the worker's response to the work place according to his/her expectations and character. The feeling expressed by the individual shows the extent of his interaction with his/her environment through the various aspects related to the factors affecting the work environment.

This research aims at identifying the strength and significance of the relationship between the job satisfaction and the work environment in higher education institutions in the Arab Republic of Egypt, and what are the most important suggestions for improving the work environment to achieve job satisfaction for the employees.

In order to achieve the objectives of the research, a questionnaire was designed to be distributed to a sample of faculty members at Ain Shams University and the New Cairo Academy, where 200 forms were distributed. The number of forms of statistical analysis was $174(87 \%)$ of the statistical methods, which are the correlation analysis and regression analysis to analyze the results of the research and test hypotheses, and the results of the research to have a positive relationship of statistically significant between the internal work environment and job satisfaction, as well as the existence of a significant impact of statistical satisfaction of the job on the work environment.
\end{abstract}

Keywords: work environment, employee satisfaction, job satisfaction.

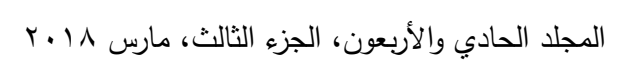

